\title{
Grain Growth and Precipitation Behavior of Iridium Alloy DOP-26 During Long-Term Aging
}

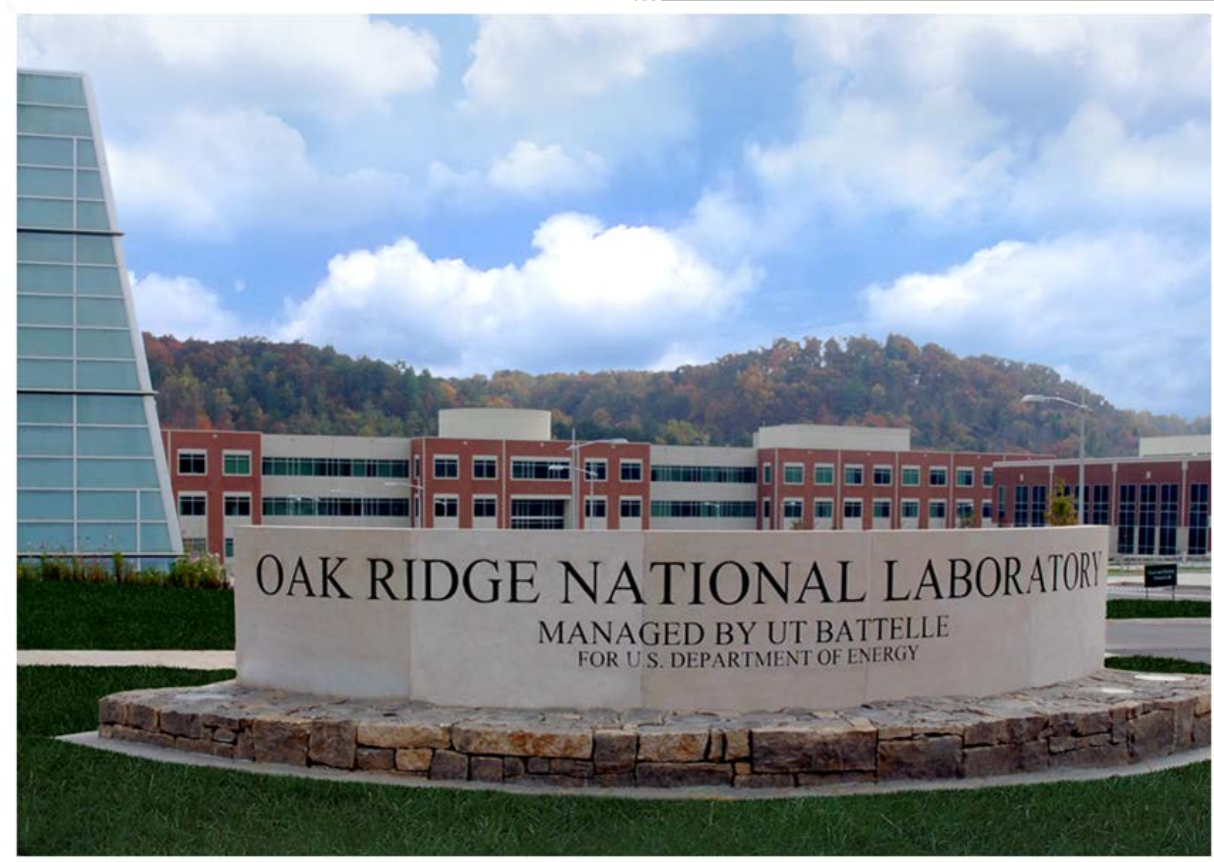

Approved for public release.

Distribution is unlimited.

D. T. Pierce

G. Muralidharan

E. E. Fox

V. A. Cox

T. S. Geer

May 2017 


\title{
DOCUMENT AVAILABILITY
}

Reports produced after January 1, 1996, are generally available free via US Department of Energy (DOE) SciTech Connect.

\section{Website http://www.osti.gov/scitech/}

Reports produced before January 1, 1996, may be purchased by members of the public from the following source:

\author{
National Technical Information Service \\ 5285 Port Royal Road \\ Springfield, VA 22161 \\ Telephone 703-605-6000 (1-800-553-6847) \\ TDD 703-487-4639 \\ Fax 703-605-6900 \\ E-mail info@ntis.gov \\ Website http://www.ntis.gov/help/ordermethods.aspx
}

Reports are available to DOE employees, DOE contractors, Energy Technology Data Exchange representatives, and International Nuclear Information System representatives from the following source:

Office of Scientific and Technical Information

PO Box 62

Oak Ridge, TN 37831

Telephone 865-576-8401

Fax 865-576-5728

E-mail reports@osti.gov

Website http://www.osti.gov/contact.html

This report was prepared as an account of work sponsored by an agency of the United States Government. Neither the United States Government nor any agency thereof, nor any of their employees, makes any warranty, express or implied, or assumes any legal liability or responsibility for the accuracy, completeness, or usefulness of any information, apparatus, product, or process disclosed, or represents that its use would not infringe privately owned rights. Reference herein to any specific commercial product, process, or service by trade name, trademark, manufacturer, or otherwise, does not necessarily constitute or imply its endorsement, recommendation, or favoring by the United States Government or any agency thereof. The views and opinions of authors expressed herein do not necessarily state or reflect those of the United States Government or any agency thereof. 


\title{
GRAIN GROWTH AND PRECIPITATION BEHAVIOR OF IRIDIUM ALLOY DOP-26 DURING LONG-TERM AGING
}

\author{
Authors: \\ D. T. Pierce \\ G. Muralidharan \\ E. E. Fox \\ V. A. Cox \\ T. S. Geer
}

Date Published: May 2017

Prepared by

OAK RIDGE NATIONAL LABORATORY

Oak Ridge, TN 37831-6283

managed by

UT-BATTELLE, LLC

for the

US DEPARTMENT OF ENERGY

under contract DE-AC05-00OR22725 



\section{CONTENTS}

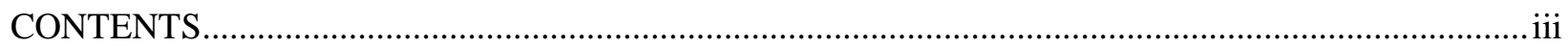

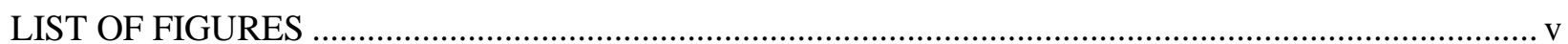

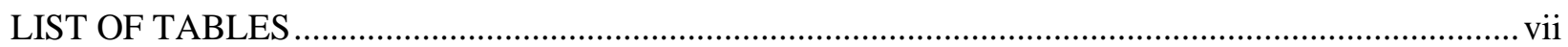

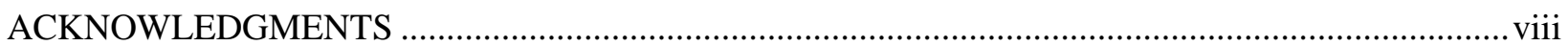

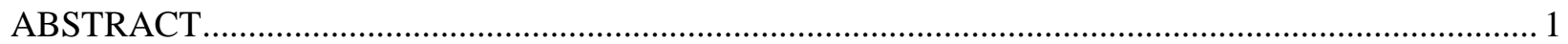

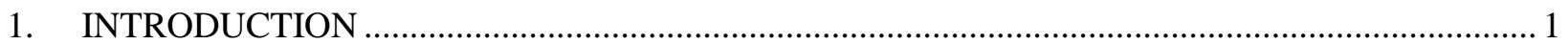

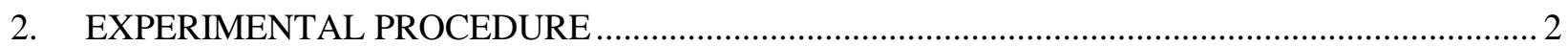

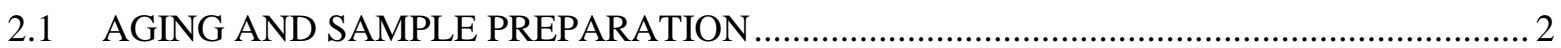

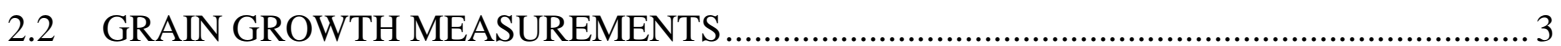

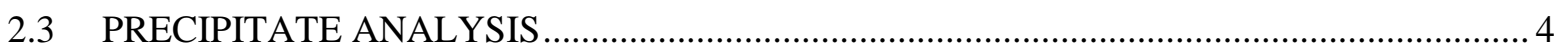

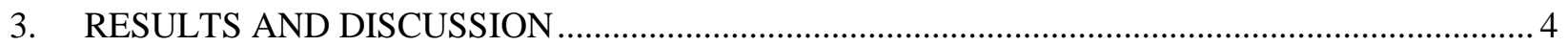

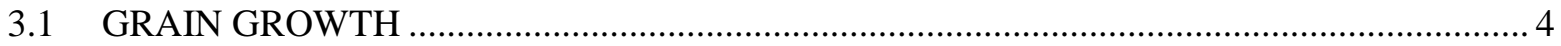

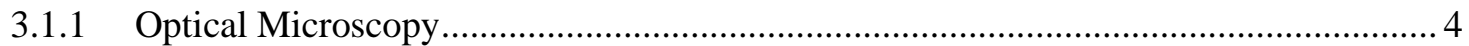

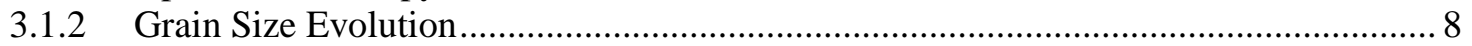

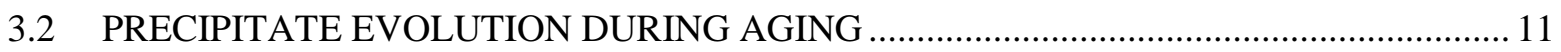

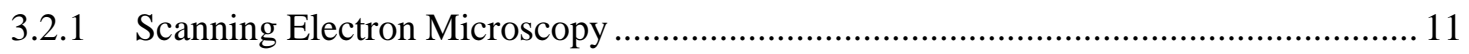

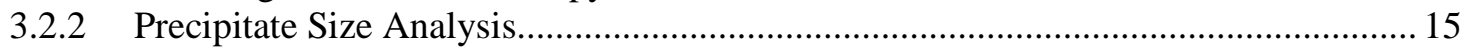

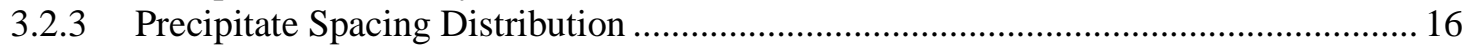

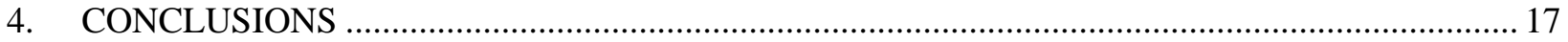

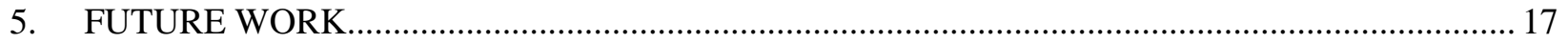

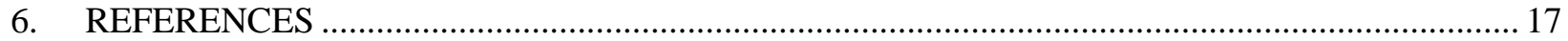

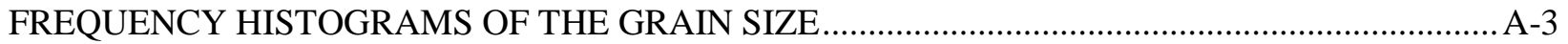

GRAPHS OF THE TWO-DIMENSIONAL PRECIPITATE LOCATIONS …................................... B-3

FREQUENCY DISTRIBUTION HISTOGRAMS OF PRECIPITATE SPACING ................................. C-3 



\section{LIST OF FIGURES}

Fig. 1. Schematic diagram showing the longitudinal section (L), transverse section (S), and rolling surface (R) as well as the rolling (RD), short transverse (ST) and long transverse

(LT) directions.

Fig. 2. Schematic diagram showing horizontal and vertical projections of a grain. .................................. 4

Fig. 3. Optical micrographs of the longitudinal sections (L) obtained for the as-recrystallized condition and after aging at 1300,1400 , and $1500{ }^{\circ} \mathrm{C}$ for the times indicated on the individual images (the rolling direction is along the horizontal).

Fig. 4. Optical micrographs of the transverse sections (S) obtained for the as-recrystallized condition and after aging at 1300,1400 , and $1500{ }^{\circ} \mathrm{C}$ for the times indicated on the individual images (the long transverse direction is along the horizontal).

Fig. 5. Optical micrographs of the rolling surface (R) obtained for the as-recrystallized condition and after aging at 1300,1400 , and $1500^{\circ} \mathrm{C}$ for the times indicated on the individual

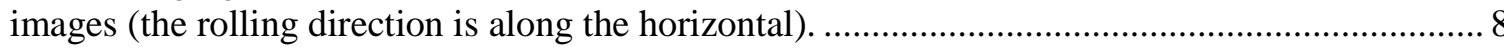

Fig. 6. As-recrystallized sample - longitudinal section. .......................................................................... 12

Fig. 7. As-recrystallized sample - digitized precipitate locations corresponding to (a) the transverse section and (b) the rolling surface.

Fig. 8. Sample aged $500 \mathrm{~h}$ at $1500^{\circ} \mathrm{C}$ - longitudinal section. 14

Fig. A1. Frequency histograms of the measured horizontal projection lengths for the L, S, and R surfaces (left to right) for the as-recrystallized condition.

Fig. A2. Frequency histograms of the measured horizontal projection lengths for the L, S, and R surfaces (left to right) after aging at $1300^{\circ} \mathrm{C}$ for $2000 \mathrm{~h}$ (top), $5000 \mathrm{~h}$ (middle), and 10,000 h (bottom).

Fig. A3. Frequency histograms of the measured horizontal projection lengths for the L, S, and R surfaces (left to right) after aging at $1400^{\circ} \mathrm{C}$ for $2000 \mathrm{~h}$ (top), $5000 \mathrm{~h}$ (middle), and 10,000 h (bottom).

Fig. A4. Frequency histograms of the measured horizontal projection lengths for the L, S, and R surfaces (left to right) after aging at $1500{ }^{\circ} \mathrm{C}$ for $200 \mathrm{~h}$ (top), $500 \mathrm{~h}$ (middle), and $1000 \mathrm{~h}$ (bottom).

Fig. A5. Frequency histograms of the measured vertical projection lengths for the L, S, and R surfaces (left to right) of the as-recrystallized condition.

Fig. A6. Frequency histograms of the measured vertical projection lengths for the L, S, and R surfaces (left to right) after aging at $1300{ }^{\circ} \mathrm{C}$ for $2000 \mathrm{~h}$ (top), $5000 \mathrm{~h}$ (middle), and 10,000 h (bottom).

Fig. A7. Frequency histograms of the measured vertical projection lengths for the L, S, and R surfaces (left to right) after aging at $1400^{\circ} \mathrm{C}$ for $2000 \mathrm{~h}$ (top), $5000 \mathrm{~h}$ (middle), and 10,000 h (bottom).

Fig. A8. Frequency histograms of the measured vertical projection lengths for the L, S, and R surfaces (left to right) after aging at $1500{ }^{\circ} \mathrm{C}$ for $200 \mathrm{~h}$ (top), $500 \mathrm{~h}$ (middle), and $1000 \mathrm{~h}$ (bottom).

Fig. B1. As-recrystallized sample - digitized precipitate locations corresponding to the (a) longitudinal section, (b) transverse section, and (c) the rolling surface.

Fig. B2. Sample aged at $1300^{\circ} \mathrm{C}$ for $2000 \mathrm{~h}$ - digitized precipitate locations corresponding to the (a) longitudinal section, (b) transverse section, and (c) the rolling surface.

Fig. B3. Sample aged at $1300{ }^{\circ} \mathrm{C}$ for $5000 \mathrm{~h}$ - digitized precipitate locations corresponding to the (a) longitudinal section, (b) transverse section, and (c) the rolling surface. 
Fig. B4. Sample aged at $1300{ }^{\circ} \mathrm{C}$ for $10,000 \mathrm{~h}$ - digitized precipitate locations corresponding to the (a) longitudinal section, (b) transverse section, and (c) the rolling surface. The horizontal is approximately along the rolling direction in (a) and (c) and the long transverse direction in (b).

Fig. B5. Sample aged at $1400{ }^{\circ} \mathrm{C}$ for $2000 \mathrm{~h}$ - digitized precipitate locations corresponding to the

(a) longitudinal section, (b) transverse section, and (c) the rolling surface......

Fig. B6. Sample aged at $1400{ }^{\circ} \mathrm{C}$ for $5000 \mathrm{~h}$ - digitized precipitate locations corresponding to the

(a) longitudinal section, (b) transverse section, and (c) the rolling surface.

Fig. B7. Sample aged at $1400{ }^{\circ} \mathrm{C}$ for $10,000 \mathrm{~h}$ - digitized precipitate locations corresponding to the (a) longitudinal section, (b) transverse section, and (c) the rolling surface.

Fig. B8. Sample aged at $1500{ }^{\circ} \mathrm{C}$ for $200 \mathrm{~h}$ - digitized precipitate locations corresponding to the (a) longitudinal section, (b) transverse section, and (c) the rolling surface.

Fig. B9. Sample aged at $1500{ }^{\circ} \mathrm{C}$ for $500 \mathrm{~h}$ - digitized precipitate locations corresponding to the

(a) longitudinal section, (b) transverse section, and (c) the rolling surface.

Fig. B10. Samples aged at $1500^{\circ} \mathrm{C}$ for $1000 \mathrm{~h}$ - digitized precipitate locations corresponding to the (a) longitudinal section, (b) transverse section, and (c) the rolling surface.

Fig. C1. As-recrystallized sample. Frequency distribution histograms of the near neighbor precipitate distances for specific angular intervals for the L, S, and R surfaces (left to right)......

Fig. C2. Samples aged at $1300{ }^{\circ} \mathrm{C}$. Frequency distribution histograms of the near neighbor precipitate distances at specific angular intervals for the $\mathrm{L}, \mathrm{S}$, and $\mathrm{R}$ surfaces (left to right) after aging times of 2000 (top), 5000 (middle), and 10,000 h (bottom).

Fig. C3. Samples aged at $1400{ }^{\circ} \mathrm{C}$. Frequency distribution histograms of the near neighbor precipitate distances at specific angular intervals for the L, S, and R surfaces (left to right) after aging times of 2000 (top), 5000 (middle), and 10,000 h (bottom).

Fig. C4. Samples aged at $1500{ }^{\circ} \mathrm{C}$. Frequency distribution histograms of the near neighbor precipitate distances at specific angular intervals for the L, S, and R surfaces (left to right) after aging times of 200 (top), 500 (middle), and $1000 \mathrm{~h}$ (bottom). 


\section{LIST OF TABLES}

Table 1. Aging temperatures and times investigated in this study signified by " $\mathrm{X}$ ” (all samples were recrystallized at $1375^{\circ} \mathrm{C}$ for $1 \mathrm{~h}$ prior to the long-term aging). All heat treatments were performed under vacuum .

Table 2. Mean projection and linear intercept lengths for longitudinal sections (L), transverse sections (S), and rolling surfaces (R) of the as-recrystallized and aged specimens (the 95\% confidence intervals are provided for the mean projection lengths and the numbers in parentheses indicate the number of grains analyzed for the projection data) 10

Table 3. Average major and minor ellipse axis lengths for the L, S and R surfaces of the asrecrystallized and aged samples. 


\section{ACKNOWLEDGMENTS}

The authors would like to acknowledge George Ulrich and Easo George for their guidance and Cecil Carmichael, Glenn Romanoski, and Brian Friske for materials processing.

This work was sponsored by the United States Department of Energy (DOE) Office of Nuclear Facilities Management (NE-31). The authors gratefully acknowledge the support and guidance of Ryan D. Bechtel of the U.S. Department of Energy.

Oak Ridge National Laboratory is a multi-program research laboratory managed by UT-Battelle, LLC, for the U.S. DOE under contract DE-AC05-00OR22725. 



\begin{abstract}
The influence of long term aging on grain growth and precipitate sizes and spatial distribution in iridium alloy DOP-26 was studied. Samples of DOP-26 were fabricated using the "new process," recrystallized for 1 hour (h) at $1375{ }^{\circ} \mathrm{C}$, then aged at either 1300,1400 , or $1500{ }^{\circ} \mathrm{C}$ for times ranging from 50 to 10,000 h. Grain size measurements (vertical and horizontal mean linear intercept and horizontal and vertical projection) and analyses of iridium-thorium precipitates (size and spacing) were made on the longitudinal, transverse, and rolling surfaces of the as-recrystallized and aged specimens from which the twodimensional spatial distribution and mean sizes of the precipitates were obtained. The results obtained from this study are intended to provide input to grain growth models.
\end{abstract}

\title{
1. INTRODUCTION
}

Iridium (Ir) alloy DOP-26 (Ir-0.3W-0.006Th-0.005Al wt.\%) is used as a fuel cladding material in radioisotope thermoelectric generators for space applications owing in part to its excellent high temperature impact ductility and good oxidation resistance [1] [2] [3] [4]. Tungsten (W) is alloyed with $\mathrm{Ir}$ to raise the recrystallization temperature, enhance fabricability and provides solid solution strengthening [1]. Doping with thorium (Th) decreases grain growth kinetics significantly, and causes a change in the fracture mode from brittle intergranular to ductile transgranular at high temperatures, resulting in increasing impact ductilities at temperatures above $\sim 650^{\circ} \mathrm{C}$ [4]. The change in fracture mode is primarily attributed to the segregation of Th to grain boundaries [4]. Th has a very low solubility limit in $\operatorname{Ir}(<30$ weight parts per million (wppm)) and addition of up to 1000 wppm Th was shown to result in the segregation of Th to grain boundaries as well as the formation of $\operatorname{Ir}_{5} T h$ precipitates [4] [5]. Th concentrations ranging from $\sim 5$ to 9 at \% have been measured at grain boundaries of DOP-26 by Auger Electron Spectroscopy (AES) [3]. Liu et al. [4] estimated that Th improves grain boundary cohesive strength by approximately $90 \%$. In addition, Th additions limit grain growth through grain boundary pinning by precipitates. Limiting grain growth in DOP-26 is important since increasing grain size promotes intergranular fracture and consequently, reduces high temperature impact ductility [4].

Given the dependence of high temperature tensile impact ductility on grain size, several investigations have focused on the influence of temperature, time, prior thermomechanical processing, and /or atmospheric conditions on the kinetics of grain growth in Ir based alloys [4] [6] [7] [8]. Harasyn and Schaffhauser [7] studied grain growth in rolled sheets of Ir- $0.3 \mathrm{wt} . \% \mathrm{~W}$ alloys with trace additions of various alloying elements, including $40 \mathrm{wppm}$ Th in an alloy designated DOP-4. Grain growth was significantly reduced in the DOP-4 alloy compared to the base Ir- $0.3 \mathrm{wt} . \% \mathrm{~W}$ alloy and the authors speculated that Th may be responsible for this reduction in grain growth kinetics. The authors reported no evidence of abnormal grain growth. Subsequently, Liu et al. [4] investigated the influence of aging temperature (1500 to $1800^{\circ} \mathrm{C}$ ), aging time (1 to $60 \mathrm{~h}$ ), and Th concentrations (up to $1000 \mathrm{wppm}$ ) on grain growth in vacuum. The authors reported that increasing amounts of Th limit grain growth due to the precipitation of $\operatorname{Ir}_{5}$ Th precipitates (which pin the grain boundaries) and possibly through a solute drag mechanism owing to Th enrichment at the grain boundaries [5] [7]. It was observed that Th additions above an effective (threshold) level of Th, which was found to increase with aging temperature and time, the grain growth rate was observed to approach zero [4].

Grain growth behavior of DOP-26 iridium in a low partial pressure oxygen atmosphere has also been investigated at temperatures of 1230,1280 , and $1330{ }^{\circ} \mathrm{C}$ for times up to $3000 \mathrm{~h}$ [8]. The authors reported that the kinetics of grain growth was accelerated in the presence of oxygen, particularly in the near 
surface grains. This behavior was attributed to the diffusion of Th to the sample surface to form thorium oxide due to the strong affinity of Th for oxygen and the resulting dissolution of $\operatorname{Ir}_{5} T h$ precipitates. Correspondingly, AES performed in their study revealed significantly lower Th concentrations at grain boundaries near the surface exposed to oxygen during annealing. More recently, McKamey et al. [6] investigated the grain growth behavior in clad vent set cups fabricated from DOP-26 used in the radioisotope thermoelectric generators. Most samples were annealed at temperatures from 1200 to 1800 ${ }^{\circ} \mathrm{C}$ for times of $1 \mathrm{~h}$ but a few samples were annealed at 1400 and $1500{ }^{\circ} \mathrm{C}$ for longer times up to $1000 \mathrm{~h}$. The authors reported no significant differences in grain growth rates at different regions in the cup compared to sheet material from which the cups were formed.

In general, although the aforementioned grain growth investigations have been limited to aging times of less than $3000 \mathrm{~h}$, the effects of longer term aging on grain growth are also of significance. In particular, the importance of the $\operatorname{Ir}_{5} \mathrm{Th}$ precipitates and their role in limiting grain growth, the influence of aging time and temperature on the volume fraction, size, morphology, inter-precipitate spacing, and coarsening behavior of the precipitates have not been the subject of previous studies. In addition, previous studies of grain growth in DOP-26 have employed parameters based on the mean linear intercept to quantify grain size. While these parameters represent average grain sizes, recent advancements in microstructural analysis software allow for the collection of greater quantities and more descriptive microstructural data, including individual grain morphologies and size distributions. This capability has the potential to improve the quantitative description of the microstructure thus providing the ability to capture statistical variation in microstructural characteristics that can be anticipated as a result of standard practices. The aforementioned data can also inform models of grain growth in DOP-26 to enable improved predictive capability. The primary goal of the present work is to quantify the influence of longer term aging on grain growth and precipitate size and spatial distribution evolution in DOP-26. The results reported in this study will provide input to grain growth models of DOP-26.

\section{EXPERIMENTAL PROCEDURE}

\subsection{AGING AND SAMPLE PREPARATION}

Prime DOP-26 iridium alloy (heats designated L1 and GR9) used in this investigation was fabricated using the so called "new process", described elsewhere [9]. The rolled specimens were recrystallized at $1375^{\circ} \mathrm{C}$ for $1 \mathrm{~h}$ in vacuum ( $<1 \times 10^{-4}$ torr). Coupons of the as-recrystallized DOP-26 iridium sheet were then aged in vacuum at 1300 and $1400{ }^{\circ} \mathrm{C}$ for times of 2000,5000 , and $10,000 \mathrm{~h}$ and at $1500{ }^{\circ} \mathrm{C}$ for times of 200,500 , and $1000 \mathrm{~h}$. The vacuum levels during the long term aging generally ranged from $10^{-6}$ to $10^{-7}$ torr. It should be noted that some of the grain sizes of samples measured in the present work aged at 1300, 1400 , and $1500{ }^{\circ} \mathrm{C}$ were systematically lower than grain sizes reported previously after aging in vacuum at the same temperatures but for shorter times [9]. To further investigate this discrepancy, two additional heats (G1 and ER10) of DOP-26 were each recrystallized at $1375{ }^{\circ} \mathrm{C}$ for $1 \mathrm{~h}$ in vacuum and aged at 1500 ${ }^{\circ} \mathrm{C}$ for 50 and $100 \mathrm{~h}$ and additional grain size measurements were made on these samples for comparison to previously reported values [9]. All aging times and temperatures are shown in Table 1 . After the aging treatments, the specimens were sectioned. The longitudinal sections $(\mathrm{L})$, transverse sections $(\mathrm{S})$, and rolling surfaces $(\mathrm{R})$ were examined for both the as-recrystallized samples and aged samples. A diagram of the surfaces and their relationship to the rolling direction is shown in Figure 1. Samples for light optical microscopy (LOM) were mechanically polished using a final step consisting of $1 \mu \mathrm{m}$ diamond paste and then electrolytically etched. While iridium is a difficult metal to mechanically polish, the following procedure was developed in order to achieve a surface polish quality suitable for the precipitate evaluation using scanning electron microscopy (SEM), albeit not completely scratch free. Samples for SEM were mechanically polished using standard mechanical polishing techniques down to a $1 \mu \mathrm{m}$ polish. 
Subsequently, the samples were vibratory polished with a $0.5 \mu \mathrm{m}$ diamond paste in a lubricant mixture of $50 \%$ ethylene glycol and 50\% distilled water on a nylon cloth for $\sim 24 \mathrm{~h}$. The final step consisted of vibratory polishing using the same type of cloth and lubricant mixture but with $0.1 \mu \mathrm{m}$ polycrystalline diamond paste for a minimum of $24 \mathrm{~h}$.

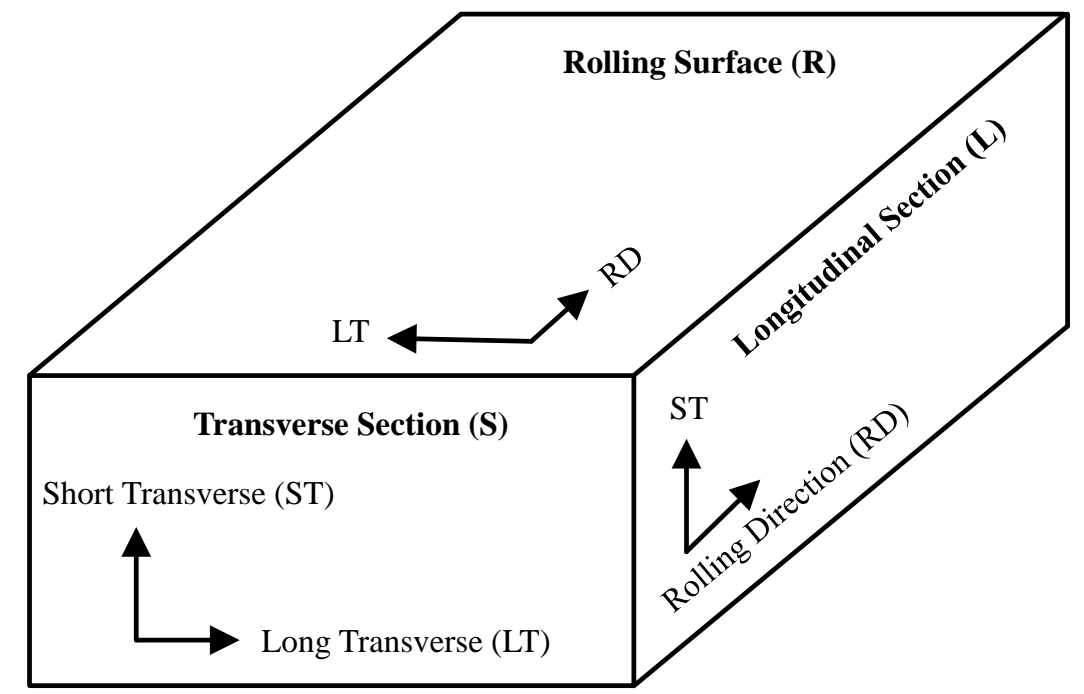

Fig. 1. Schematic diagram showing the longitudinal section (L), transverse section (S), and rolling surface $(R)$ as well as the rolling (RD), short transverse (ST) and long transverse (LT) directions.

Table 1. Aging Temperatures and Times Investigated in this Study Signified by " $X$ " (all samples were recrystallized at $1375{ }^{\circ} \mathrm{C}$ for $1 \mathrm{~h}$ prior to the long-term aging) All Heat Treatments Were Performed Under Vacuum

\begin{tabular}{|c|c|c|c|c|c|c|c|c|c|}
\hline & & \multicolumn{7}{|c|}{ Aging Time (h) } \\
\hline $\begin{array}{c}\text { Aging } \\
\text { Temperature } \\
\left({ }^{\circ} \mathbf{C}\right)\end{array}$ & $\begin{array}{c}\text { As- } \\
\text { recrystallized }\end{array}$ & $\mathbf{5 0}$ & $\mathbf{1 0 0}$ & $\mathbf{2 0 0}$ & $\mathbf{5 0 0}$ & $\mathbf{1 0 0 0}$ & $\mathbf{2 0 0 0}$ & $\mathbf{5 0 0 0}$ & $\mathbf{1 0 , 0 0 0}$ \\
\hline N/A & $\mathrm{X}$ & & & & & & & & \\
\hline 1300 & & & & & & & $\mathrm{X}$ & $\mathrm{X}$ & $\mathrm{X}$ \\
\hline 1400 & & & & & & & $\mathrm{X}$ & $\mathrm{X}$ & $\mathrm{X}$ \\
\hline 1500 & & $\mathrm{X}$ & $\mathrm{X}$ & $\mathrm{X}$ & $\mathrm{X}$ & $\mathrm{X}$ & & & \\
\hline
\end{tabular}

\subsection{GRAIN GROWTH MEASUREMENTS}

Evaluation of the optical micrographs was performed using Leica Application Suite (LAS). This software has a variety of parameters available to characterize grain structure. The parameters used to quantify grain size in this work are the mean linear intercept (MLI), as per American Society for Testing Materials (ASTM) E112-12, and the horizontal and vertical projections. Mean linear intercept was calculated in both the horizontal and vertical directions. The horizontal MLI is calculated along the RD on the longitudinal section and rolling surface and along the LT direction on the transverse section while the vertical MLI is along the ST direction for the longitudinal and transverse sections and the LT direction for the rolling surface. The horizontal and vertical projections are defined as the lengths of the shadow cast if 
light were impinging on the grain from a horizontal or vertical direction. For clarity, a diagram of the horizontal and vertical projections is presented in Figure 2. No rotation of the grain is performed in determining the vertical or horizontal projections. The vertical projection captures the grain size along the $\mathrm{RD}$ on the longitudinal section and rolling surface and along the LT direction on the transverse section. The horizontal projection captures grain size along the ST direction for the longitudinal and transverse sections and the LT direction for the rolling surface. Thus, vertical MLI and horizontal projection describe grain size in the same direction for a given surface in this study and vice versa.

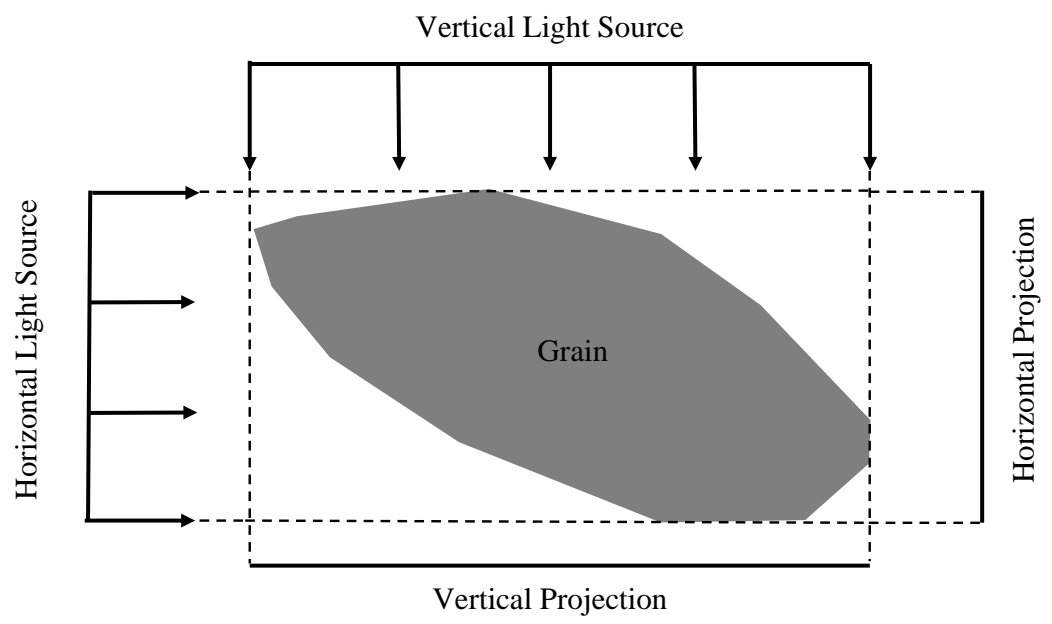

Fig. 2. Schematic diagram showing horizontal and vertical projections of a grain.

\subsection{PRECIPITATE ANALYSIS}

SEM was performed on each of the three surfaces for the heat treatment conditions listed in Table 1 to quantify precipitate size and spatial distribution (with the exception of the samples aged for 50 and $100 \mathrm{~h}$ at $1500{ }^{\circ} \mathrm{C}$ that were used only to make additional grain size measurements). To enable quantification of the precipitate spacing distribution as a function of aging time, high resolution (5120 x 3840 pixels) low magnification (500x) SEM images were recorded and stitched together to form larger montages. This method allowed precipitates with sizes of $\sim 200 \mathrm{~nm}$ or greater to be identified. For the $\mathrm{L}$ and $\mathrm{S}$ surfaces, each montage encompasses a rectangular area of $\sim 1.1 \mathrm{~mm}$ x $0.5 \mathrm{~mm}$. For the rolling surface, each montage encompasses an area of $\sim 0.95 \mathrm{~mm}$ x $0.7 \mathrm{~mm}$. A minimum of two montages were obtained from each surface of each condition so that the total area examined was greater than $\sim 1 \mathrm{~mm}^{2}$. The coordinates of individual precipitate locations on the montage were then digitized for subsequent analysis of the interprecipitate spacing. The precipitate sizes were measured from images recorded at a magnification of $4000 x$ or greater. These images were recorded from different areas of the specimen. Approximately 100 or more precipitates were measured for each orientation of each heat treatment condition.

\section{RESULTS AND DISCUSSION}

\subsection{GRAIN GROWTH}

\subsubsection{Optical Microscopy}

Light optical micrographs were recorded for the longitudinal section, transverse section, and rolling surface of each condition and are shown in Figures 3, 4, and 5, respectively. The images shown are 
smaller representative sections of much larger montages. Note that any change in contrast or brightness on a given image is an artifact of multiple images being stitched together. All images were recorded under identical conditions and differences in contrast or brightness between images is due to post-capture editing in order to streamline the analysis. There is some variation in thickness in the short transverse direction due to slight differences in the thickness of the blanks from which a sample was cut. The rolling surface of all samples was larger than the field of view of the microscope so the images shown are cropped from an interior area of the original composite image and have the same magnification.

It should be noted that in some of the aged conditions, relatively large grains were more prevalent near the edge of the sample while smaller grains appeared to be more concentrated near the mid-thickness of the longitudinal and transverse sections. This non-homogenous spatial distribution of grain sizes within a single sample was most evident in the conditions with the largest average grain sizes. For instance, the effect is visible in the micrographs of the longitudinal sections of samples aged at $1400{ }^{\circ} \mathrm{C}$ for $10,000 \mathrm{~h}$ and at $1500{ }^{\circ} \mathrm{C}$ for $1000 \mathrm{~h}$ (see Figure 3). The cause of this behavior in the present work is not clear at this time. In previous work [9], aging was performed at temperatures ranging from 1230 to $1330{ }^{\circ} \mathrm{C}$ for times up to $3000 \mathrm{~h}$ while exposed to an oxygen partial pressure of $1.0 \times 10^{-5}$ torr. In the same study, aging was also performed at $1330{ }^{\circ} \mathrm{C}$ for up to $3000 \mathrm{~h}$ while exposed to an oxygen partial pressure of $1.0 \times 10^{-4}$ torr. Under these conditions, accelerated grain growth was observed in near surface grains. In the present study, the levels of oxygen in the atmosphere during aging are lower than in the aforementioned study [9] by approximately one to three orders of magnitude but the aging temperatures and/or times are higher and longer, respectively. Therefore, it is not clear if oxygen, even present at lower levels compared to previous studies, affected grain growth behavior during aging in the present study. Further investigation into the cause of this behavior is proposed for future work. 


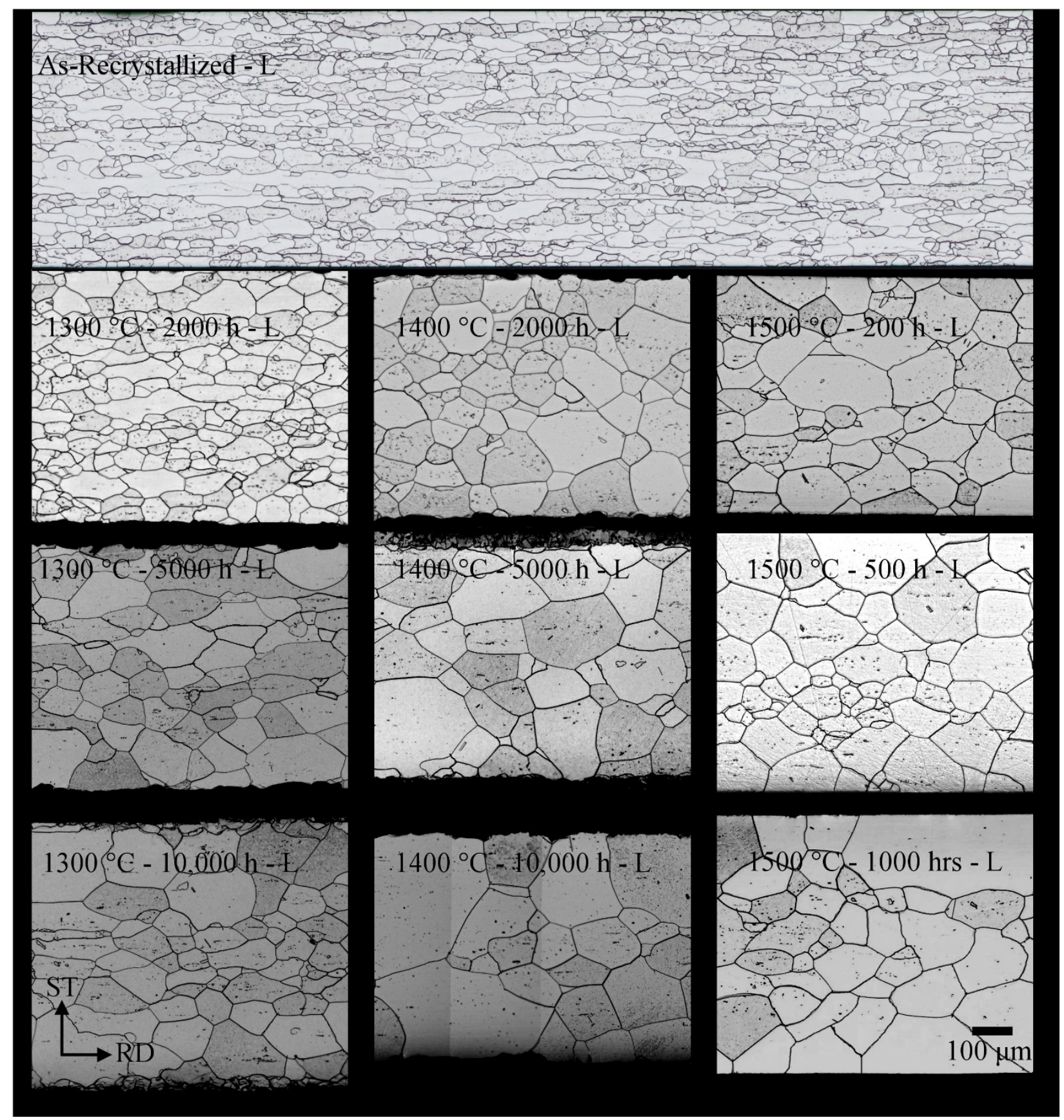

Fig. 3. Optical micrographs of the longitudinal sections ( $\mathrm{L}$ ) obtained for the as-recrystallized condition and after aging at 1300,1400 , and $1500{ }^{\circ} \mathrm{C}$ for the times indicated on the individual images (the rolling direction is along the horizontal). 


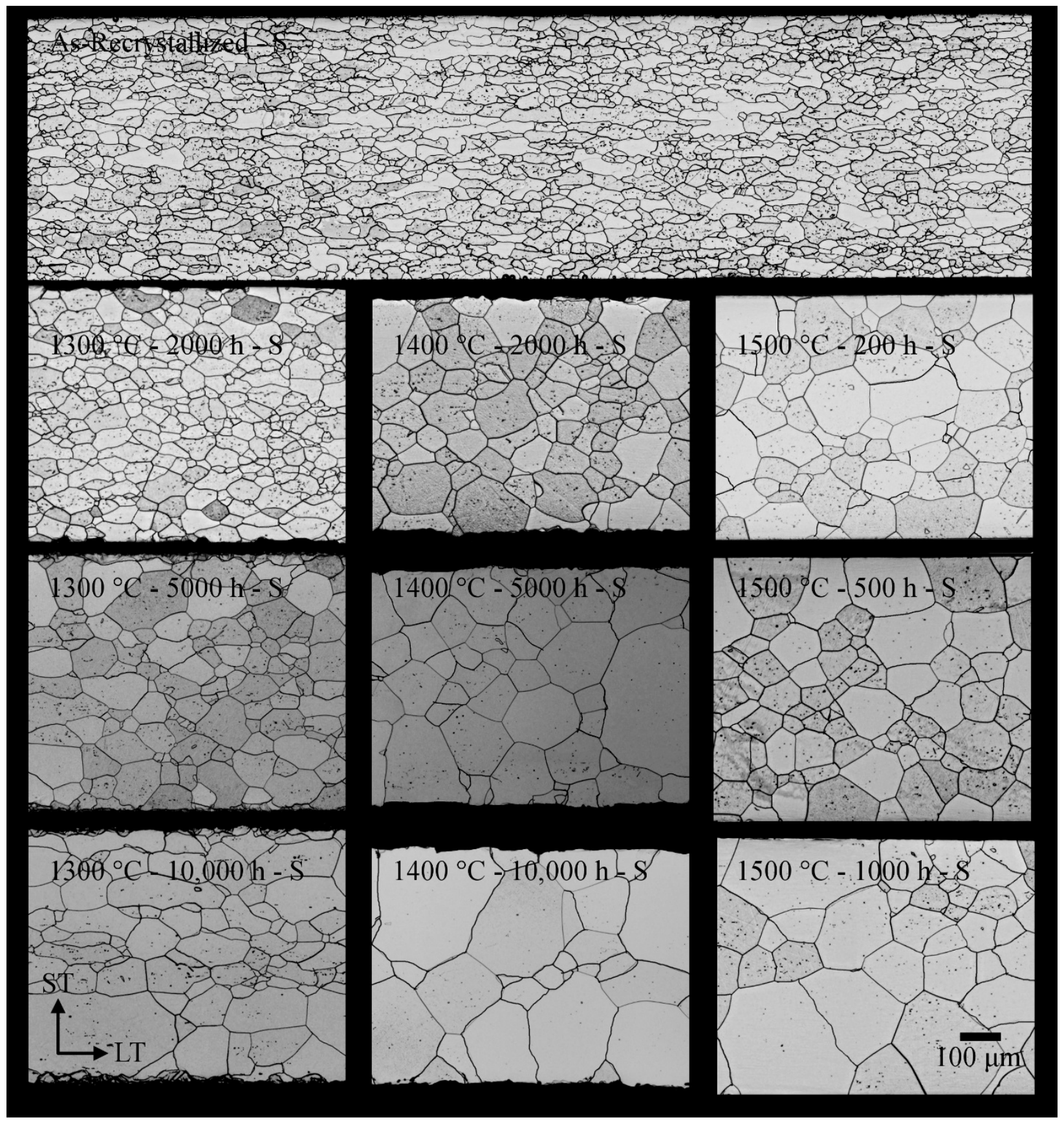

Fig. 4. Optical micrographs of the transverse sections (S) obtained for the as-recrystallized condition and after aging at 1300,1400 , and $1500{ }^{\circ} \mathrm{C}$ for the times indicated on the individual images (the long transverse direction is along the horizontal). 


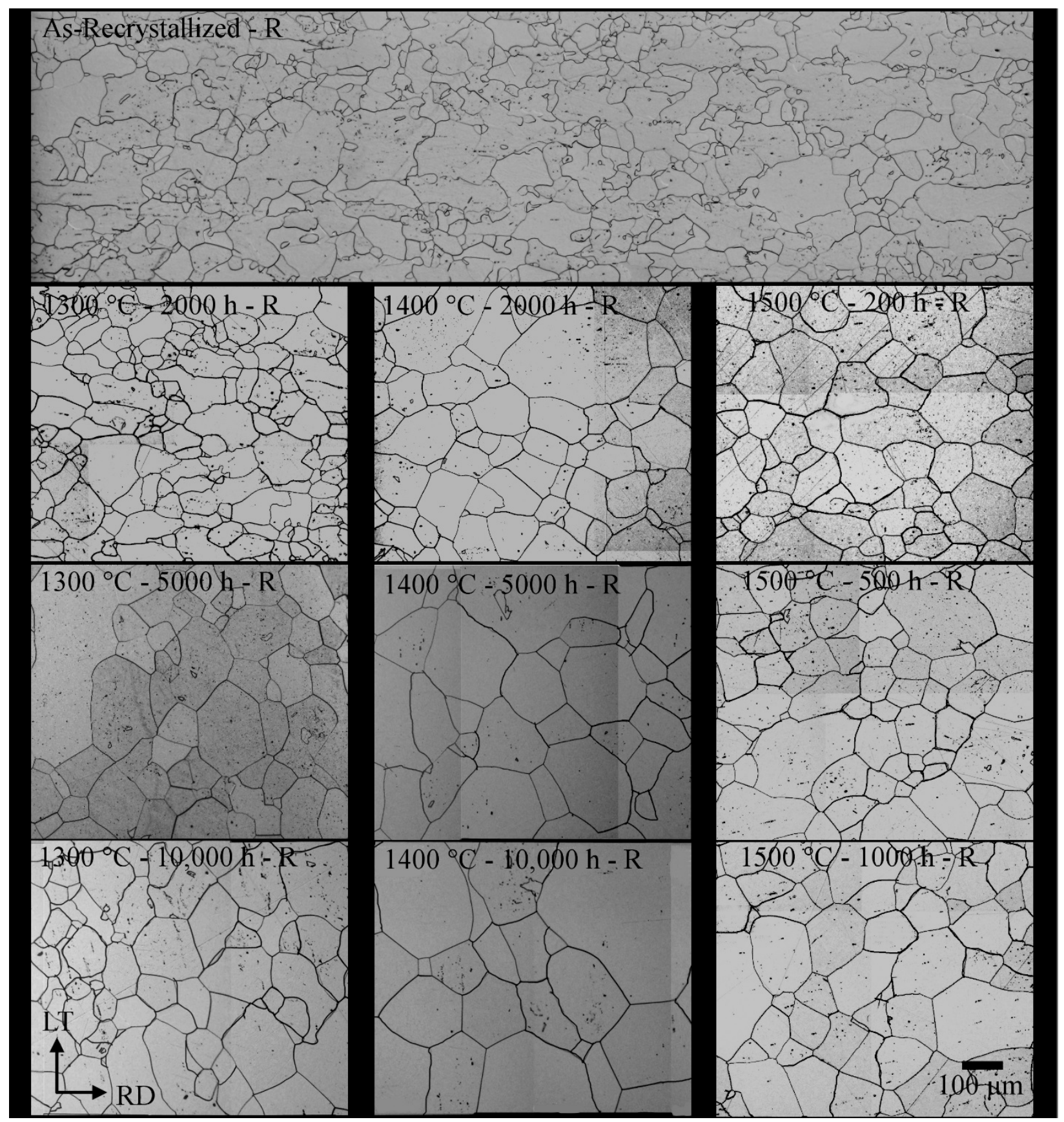

Fig. 5. Optical micrographs of the rolling surface (R) obtained for the as-recrystallized condition and after aging at 1300,1400 , and $1500{ }^{\circ} \mathrm{C}$ for the times indicated on the individual images (the rolling direction is along the horizontal).

\subsubsection{Grain Size Evolution}

Vertical and horizontal MLI as well as average horizontal and vertical projection lengths were obtained for each orientation of samples aged for 200, 500, 1000, 2000, 5000, and 10,000 h and are presented in Table 2. Mean linear intercept has been used previously to quantify average grain size in DOP-26. While the MLI method is consistent with past investigations of grain size in DOP-26, it does not capture the size of all grains. In contrast, the horizontal and vertical projection lengths are calculated for every grain in the 
micrograph, resulting in better statistics and an improved characterization of grain size distribution, which can be particularly important in specimens with larger but fewer grains. It should be noted that the sample edges on the $\mathrm{L}$ and $\mathrm{S}$ surfaces were included on micrographs and these edges were treated as grain boundaries in determining the horizontal and vertical projection. Conversely, the rolling surface extends beyond the image boundary so only a portion of some grains on the image border are included in the image. In this case, the image border was treated as a grain boundary.

Also included in Table 2 are the additional grain size measurements made on the longitudinal and transverse sections of heats G1 and ER10 after aging at $1500{ }^{\circ} \mathrm{C}$ for 50 and $100 \mathrm{~h}$ and previous MLI data reported for a sample from heat $\mathrm{D} 2$ aged at $1500{ }^{\circ} \mathrm{C}$ for $100 \mathrm{~h}$ [9]. The grain size measurements made on heats G1 and ER10 after aging for 50 and $100 \mathrm{~h}$ in the same furnace follow a consistent trend when compared to the grain size of the as-recrystallized specimens and those specimens aged at $1500{ }^{\circ} \mathrm{C}$ for $200 \mathrm{~h}$ or longer in the present work. The difference in grain size between heats G1 and ER10 ranged from $\sim 0.1$ to $11 \%$ and 3 to $25 \%$ for mean projection lengths and mean linear intercept, respectively, when comparing measurements made on the same surfaces after the same aging time. The V-MLI (through thickness) values measured for heats G1 and ER10 were 26 and 32\% lower, respectively, than the value of $71 \mu \mathrm{m}$ reported previously as measured on the transverse sections after aging at $1500{ }^{\circ} \mathrm{C}$ for $100 \mathrm{~h}$ [9]. The differences in the MLI values between specimens aged at $1500{ }^{\circ} \mathrm{C}$ for $100 \mathrm{~h}$ in the present work and that reported previously [9] are likely due to the material being from different heats, uncertainty in the grain size measurements, and the use of different furnaces.

Frequency distribution histograms of the horizontal and vertical projection lengths were generated for all orientations of the conditions aged from 200 to 10,000 h and are presented in Appendix A. The horizontal projection lengths exhibit a narrower range of size compared to the vertical projection lengths, particularly for the longitudinal and transverse orientations. With increasing aging times, the distribution of grain sizes broadens for all orientations. 
Table 2. Mean Projection and Linear Intercept Lengths for Longitudinal Sections (L), Transverse Sections

(S), and Rolling Surfaces (R) of the As-Recrystallized and Aged Specimens (the 95\% confidence intervals are provided for the mean projection lengths and the numbers in parentheses indicate the number of grains analyzed for the projection data)

\begin{tabular}{|c|c|c|c|c|c|c|c|c|}
\hline $\begin{array}{c}\text { Aging } \\
\text { Temperature } \\
\left({ }^{\circ} \mathbf{C}\right)\end{array}$ & $\begin{array}{c}\text { Aging } \\
\text { Time } \\
\text { (h) }\end{array}$ & Surface & $\begin{array}{l}\text { Mean H. } \\
\text { Projection } \\
(\mu \mathrm{m})\end{array}$ & $\begin{array}{c}95 \% \\
\text { Conf. } \\
\text { Int. } \\
( \pm \mu \mathrm{m})\end{array}$ & $\begin{array}{l}\text { V - } \\
\text { MLI } \\
(\mu \mathrm{m})\end{array}$ & $\begin{array}{l}\text { Mean V. } \\
\text { Projection } \\
(\mu \mathrm{m})\end{array}$ & $\begin{array}{c}95 \% \\
\text { Conf. } \\
\text { Int. } \\
( \pm \mu \mathrm{m})\end{array}$ & $\begin{array}{c}\text { H - MLI } \\
(\mu \mathbf{m})\end{array}$ \\
\hline \multirow{3}{*}{$\begin{array}{c}\text { As } \\
\text { Recrystallized }\end{array}$} & \multirow{3}{*}{$\mathrm{n} / \mathrm{a}$} & $\mathrm{L}$ & 24.8 (5656) & 0.5 & 21.9 & 49.9 & 1.2 & 42.6 \\
\hline & & $\mathrm{S}$ & 26.6 (6500) & 0.4 & 23.2 & 46.2 & 0.8 & 37.4 \\
\hline & & $\mathrm{R}$ & $49.8(2700)$ & 1.4 & 40.7 & 61.0 & 2.0 & 46.5 \\
\hline \multirow{3}{*}{1300} & 2000 & \multirow{3}{*}{$\mathrm{L}$} & 39.5 (3448) & 0.7 & 31.5 & 69.7 & 1.6 & 58.8 \\
\hline & 5000 & & 62.6 (1781) & 1.7 & 46.8 & 98.1 & 3.0 & 84.4 \\
\hline & 10,000 & & 61.9 (2316) & 1.7 & 54.3 & 92.7 & 2.6 & 85.7 \\
\hline \multirow{3}{*}{1300} & 2000 & \multirow{3}{*}{ S } & 37.8 (2557) & 0.8 & 31.4 & 58.3 & 1.4 & 49.1 \\
\hline & 5000 & & 56.6 (3351) & 1.1 & 43.9 & 77.3 & 2.1 & 69.6 \\
\hline & 10,000 & & $63.4(3507)$ & 1.3 & 53.6 & 94.0 & 2.0 & 90.6 \\
\hline \multirow{3}{*}{1300} & 2000 & \multirow{3}{*}{$\mathrm{R}$} & $54.8(2580)$ & 1.4 & 43.3 & 67.4 & 1.9 & 56.4 \\
\hline & 5000 & & 79.0 (1001) & 3.2 & 72.7 & 96.0 & 3.9 & 84.3 \\
\hline & 10,000 & & $86.2(1520)$ & 2.8 & 79.5 & 94.8 & 3.2 & 82.4 \\
\hline \multirow{3}{*}{1400} & 2000 & \multirow{3}{*}{$\mathrm{L}$} & 75.7 (752) & 3.3 & 62.4 & 106.5 & 5.1 & 90.6 \\
\hline & 5000 & & 111.3 (694) & 5.6 & 96.7 & 144.1 & 7.1 & 145.7 \\
\hline & 10,000 & & $120.3(642)$ & 6.7 & 102.2 & 151.2 & 8.3 & 148.8 \\
\hline \multirow{3}{*}{1400} & 2000 & \multirow{3}{*}{ S } & 69.9 (559) & 3.2 & 62.9 & 87.5 & 4.0 & 70.7 \\
\hline & 5000 & & 105.7 (1433) & 3.7 & 99.7 & 124.4 & 4.2 & 115.2 \\
\hline & 10,000 & & 114.7 (1119) & 4.6 & 111.4 & 133.5 & 5.2 & 123.4 \\
\hline \multirow{3}{*}{1400} & 2000 & \multirow{3}{*}{$\mathrm{R}$} & 90.2 (839) & 4.2 & 74.8 & 98.8 & 4.8 & 78.4 \\
\hline & 5000 & & $128.2(770)$ & 5.9 & 119.9 & 136.5 & 6.2 & 109.9 \\
\hline & 10,000 & & 133.5 (324) & 11.4 & 126.6 & 167.3 & 13.5 & 163.2 \\
\hline \multirow{7}{*}{1500} & $50 *$ & \multirow{7}{*}{$\mathrm{L}$} & $57.6(969)$ & 2.4 & 44.4 & 91.2 & 3.9 & 76.4 \\
\hline & $50 * *$ & & 64.4 (947) & 2.8 & 55.5 & 89.2 & 3.9 & 74.1 \\
\hline & $100 *$ & & 60.8 (659) & 3.0 & 49.2 & 95.9 & 4.8 & 81.6 \\
\hline & $100^{* *}$ & & 65.7 (1049) & 2.4 & 56.9 & 91.3 & 3.5 & 74.6 \\
\hline & 200 & & $65.0(835)$ & 2.7 & 62.5 & 100.1 & 4.5 & 88.4 \\
\hline & 500 & & 73.9 (881) & 3.0 & 69.4 & 105.1 & 4.6 & 94.9 \\
\hline & 1000 & & $99.0(508)$ & 5.9 & 82.8 & 137.1 & 8.5 & 121.7 \\
\hline \multirow{8}{*}{1500} & $50 *$ & \multirow{8}{*}{ S } & 54.4 (919) & 2.1 & 45.9 & 77.5 & 3.2 & 60.6 \\
\hline & $50 * *$ & & 56.7 (751) & 2.5 & 48.9 & 75.8 & 3.3 & 57.9 \\
\hline & $100 *$ & & $60.1(830)$ & 2.4 & 52.3 & 79.8 & 3.2 & 66.5 \\
\hline & $100 * *$ & & 63.5 (488) & 3.4 & 48.4 & 80.0 & 4.4 & 71.0 \\
\hline & $100 * * *$ & & N/A & N/A & 71 (153) & N/A & N/A & N/A \\
\hline & 200 & & 67.4 (1168) & 2.2 & 65.9 & 86.4 & 3.0 & 73.9 \\
\hline & 500 & & 76.1 (982) & 3.0 & 74.1 & 92.7 & 3.6 & 83.4 \\
\hline & 1000 & & $90.3(672)$ & 4.0 & 85.1 & 113.6 & 5.2 & 99.0 \\
\hline \multirow{3}{*}{1500} & 200 & \multirow{3}{*}{$\mathrm{R}$} & 86.5 (1128) & 3.2 & 73.6 & 96.3 & 3.9 & 89.2 \\
\hline & 500 & & $90.4(822)$ & 3.9 & 72.4 & 102.1 & 4.5 & 90.4 \\
\hline & 1000 & & 97.5 (963) & 3.9 & 83.2 & 104.5 & 4.4 & 98.7 \\
\hline
\end{tabular}




\subsection{PRECIPITATE EVOLUTION DURING AGING}

\subsubsection{Scanning Electron Microscopy}

Scanning electron microscopy was performed at low magnification (500x) to determine the interprecipitate spacing and at higher magnification (>4000x) to determine precipitate size. Figure 6a shows a montage of SEM images (500x) recorded from the longitudinal section of the as-recrystallized sample. The precipitates typically exhibit bright contrast relative to the matrix in the back-scatter electron (BSE) imaging mode. The corresponding locations of all identifiable precipitates in Figure 6a are displayed in Figure 6b. As observed in Figure 6b, the distribution of precipitates exhibits significant clustering. These clusters or stringers, as previously described [9], contain closely spaced precipitates or strings of precipitates aligned approximately along the rolling direction. The length of these stringers was observed to be $\sim 100 \mu \mathrm{m}$ on the longitudinal section of the as-recrystallized sample. The individual precipitates themselves contained in these stringers may also be elongated along the rolling direction. Figures $6 \mathrm{c}$ and $\mathrm{d}$ show higher magnification images of the precipitate stringers observed on the longitudinal section of the as-recrystallized sample. In Figures $7 \mathrm{a}$ and $b$, the digitized precipitate locations from SEM montages of the transverse section and rolling surface of the as-recrystallized condition are shown, respectively. Precipitate stringers were observed on the rolling surface but not on the transverse section. Qualitatively, a significantly lower area number density of precipitates was observed on the rolling surface compared to the longitudinal and transverse sections of the as-recrystallized condition. The differences may be due in part due to thermo-mechanical processing, which influences the morphology of the precipitates and how they are oriented with respect to the longitudinal, transverse, and rolling surfaces.

Figure 8a shows a montage of SEM images recorded from the longitudinal section of the sample aged at $1500{ }^{\circ} \mathrm{C}$ for $500 \mathrm{~h}$. The locations of the individual precipitates in Figure 8a are shown in Figure 8b. Precipitate stringers are still observed in the sample aged at $1500{ }^{\circ} \mathrm{C}$ for $500 \mathrm{~h}$. Figure 8c is a BSE SEM image of three precipitates aligned along the rolling direction with spacing between the precipitates of $\sim 5$ $\mu \mathrm{m}$. The observed sizes of these precipitates in Figure 8c are approximately $500 \mathrm{~nm}$. In contrast, a larger precipitate with observed major axis length of $\sim 3 \mu \mathrm{m}$ is shown in Figure $8 \mathrm{~d}$. It should be noted that the measured size of the precipitates in Figure 8c are relatively small compared to the mean precipitate size measured for this condition. In addition, the measured size of the precipitate in Figure 8d is relatively large compared to the mean size measured for this condition. Qualitatively, the observed major axis of precipitates often appeared to be closely aligned with the rolling direction. 


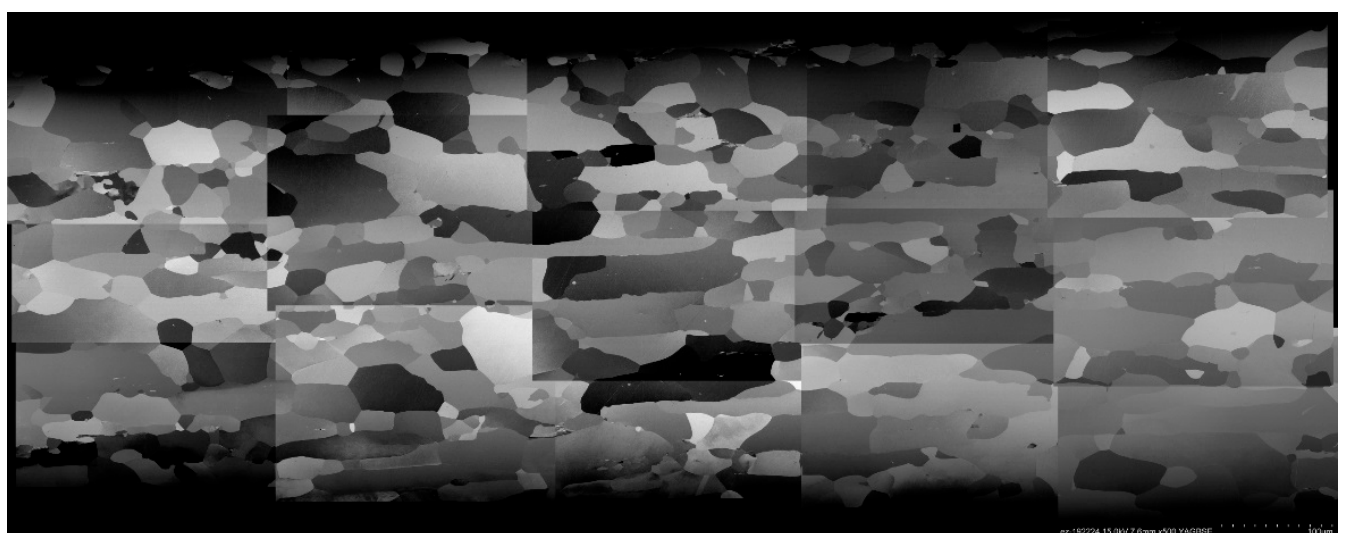

(a)

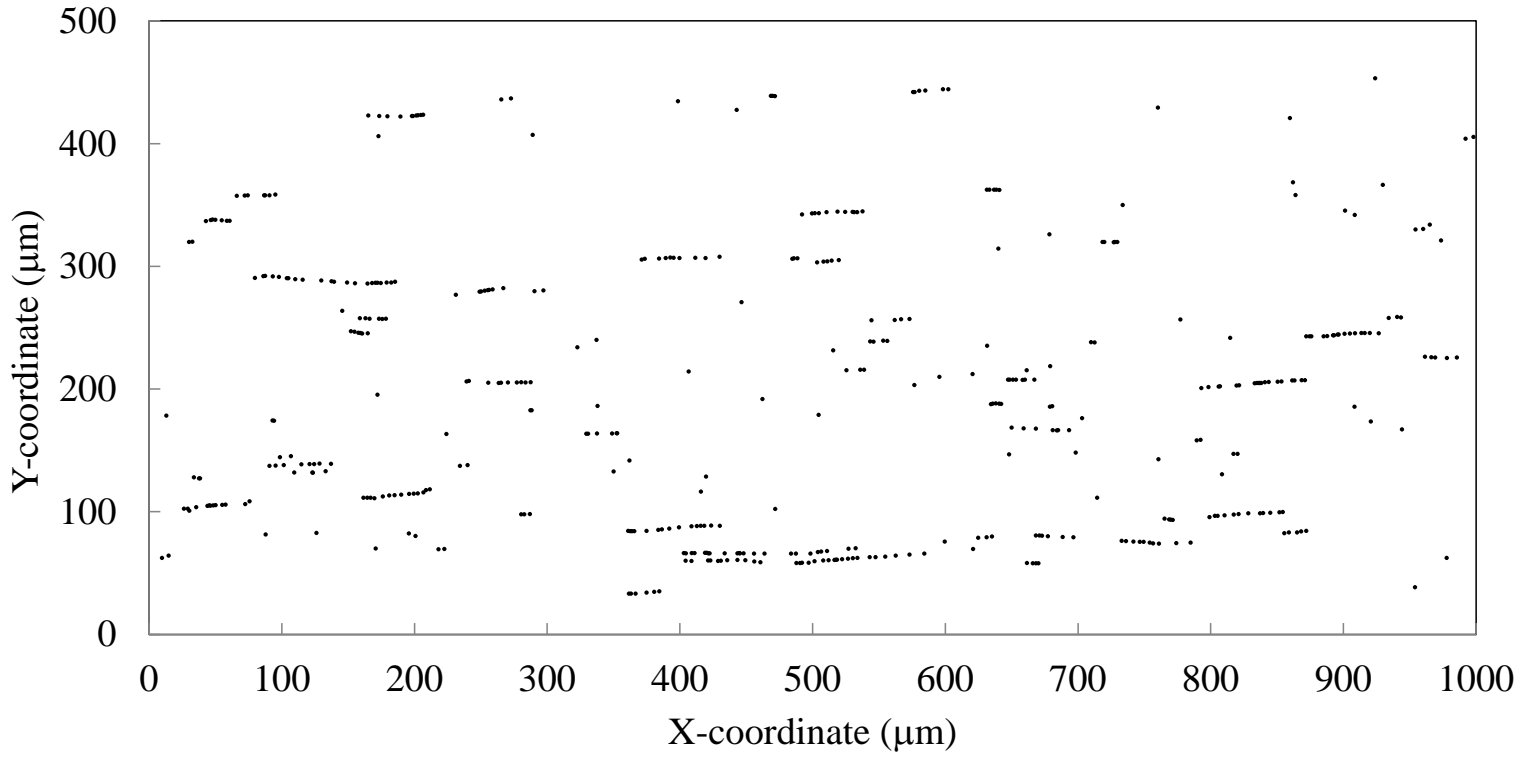

(b)

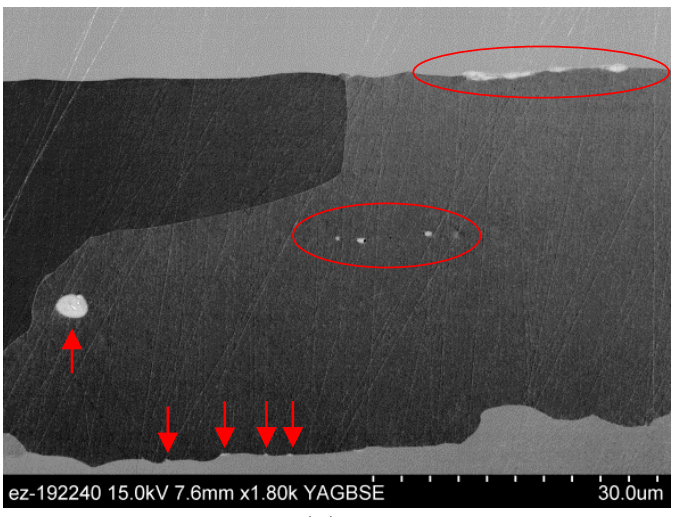

(c)

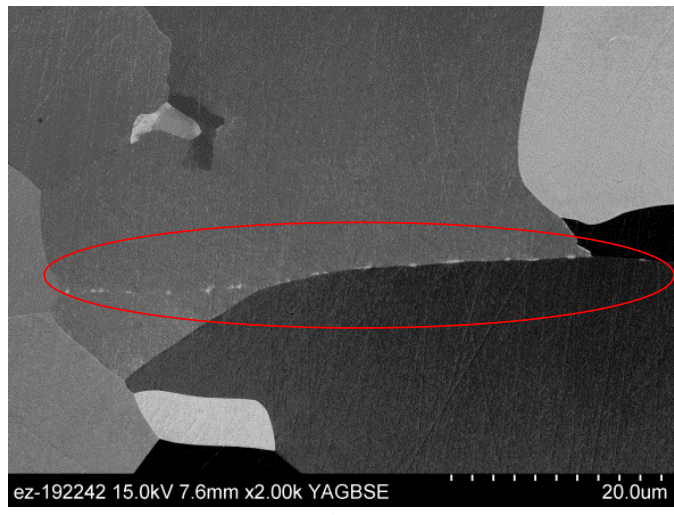

(d)

Fig. 6. As-recrystallized sample - longitudinal section. (a) SEM montage (note: the resolution of this montage has been reduced compared to the original used in the data analysis) and (b) digitized precipitate locations cor-responding to the SEM montage in (a) (note: the center of each dot represents the location of a single precipitate). (c) and (d) are higher magnification BSE SEM images showing in (c) precipitates (identified by arrows) and in (c) and (d) precipitate stringers (circled) both internal to the grains and on grain boundaries. The rolling direction is along the horizontal of all figures. 


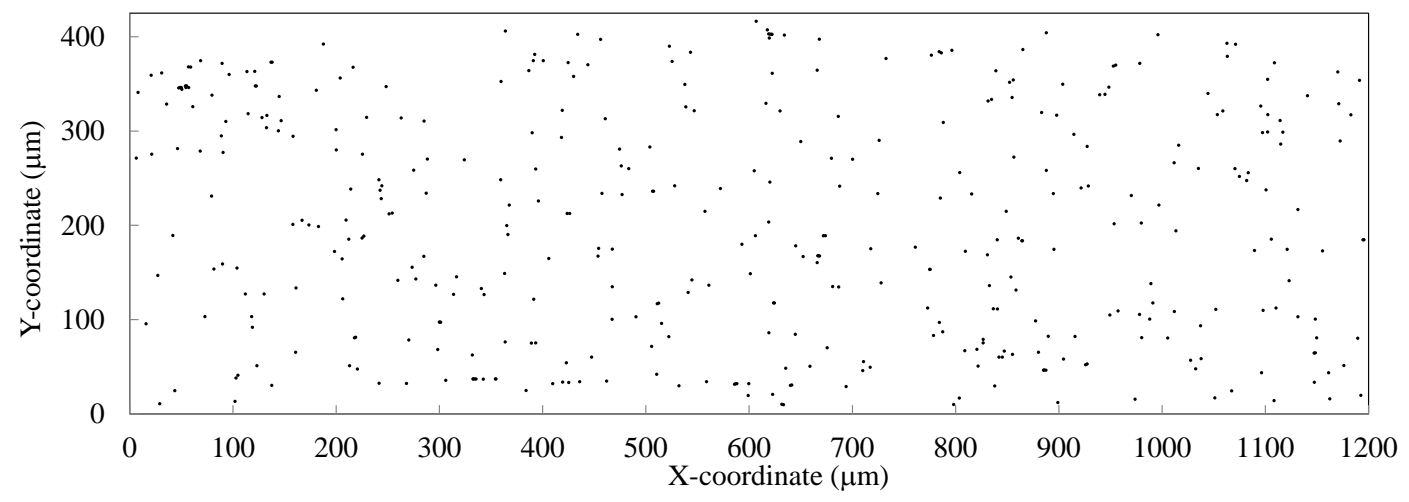

(a)

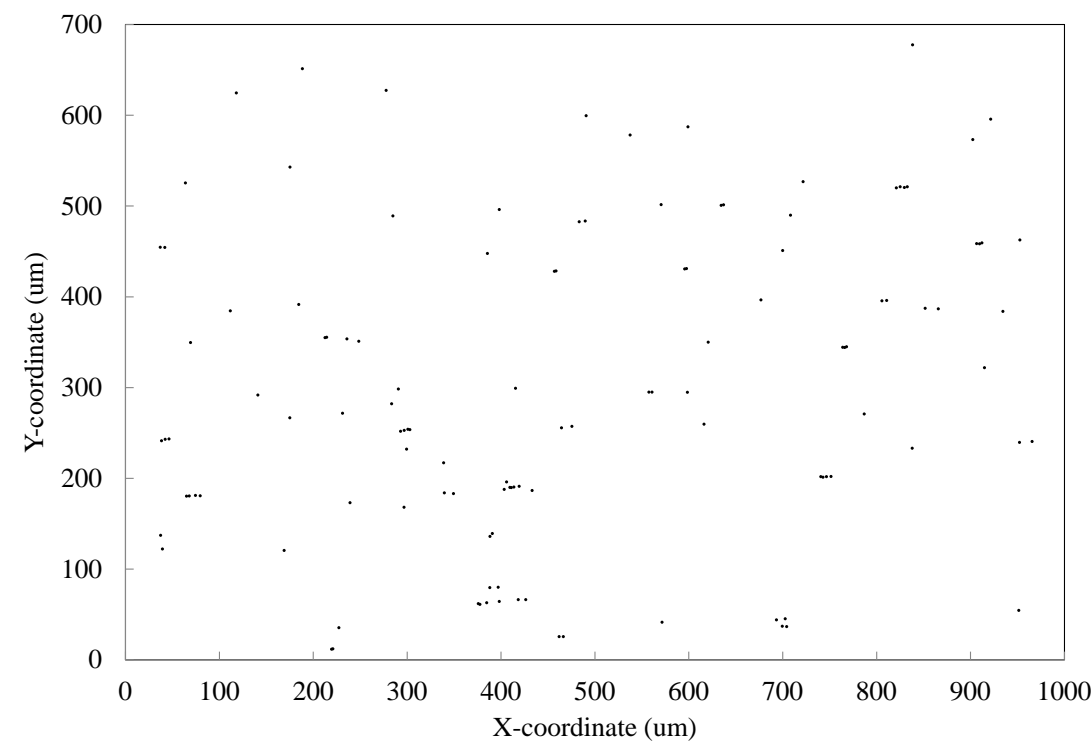

(b)

Fig. 7. As-recrystallized sample - digitized precipitate locations corresponding to (a) the transverse section and (b) the rolling surface. The long transverse and rolling directions are along the horizontals in (a) and (b), respectively. The center of each dot represents the location of a single precipitate. 


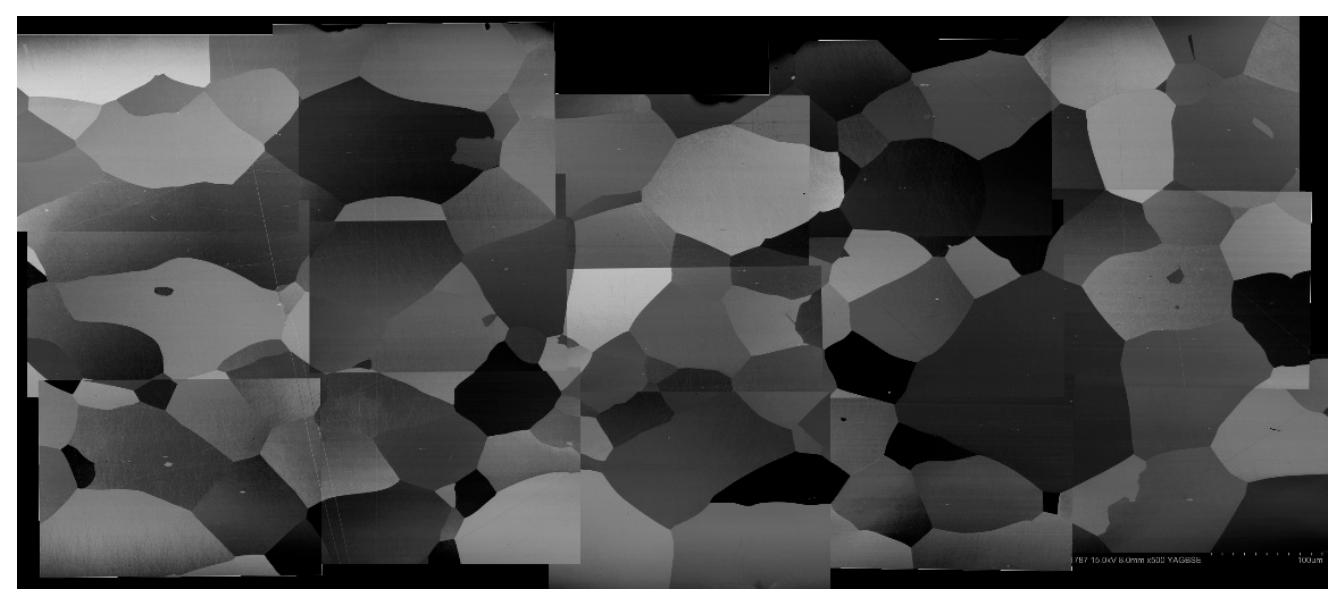

(a)

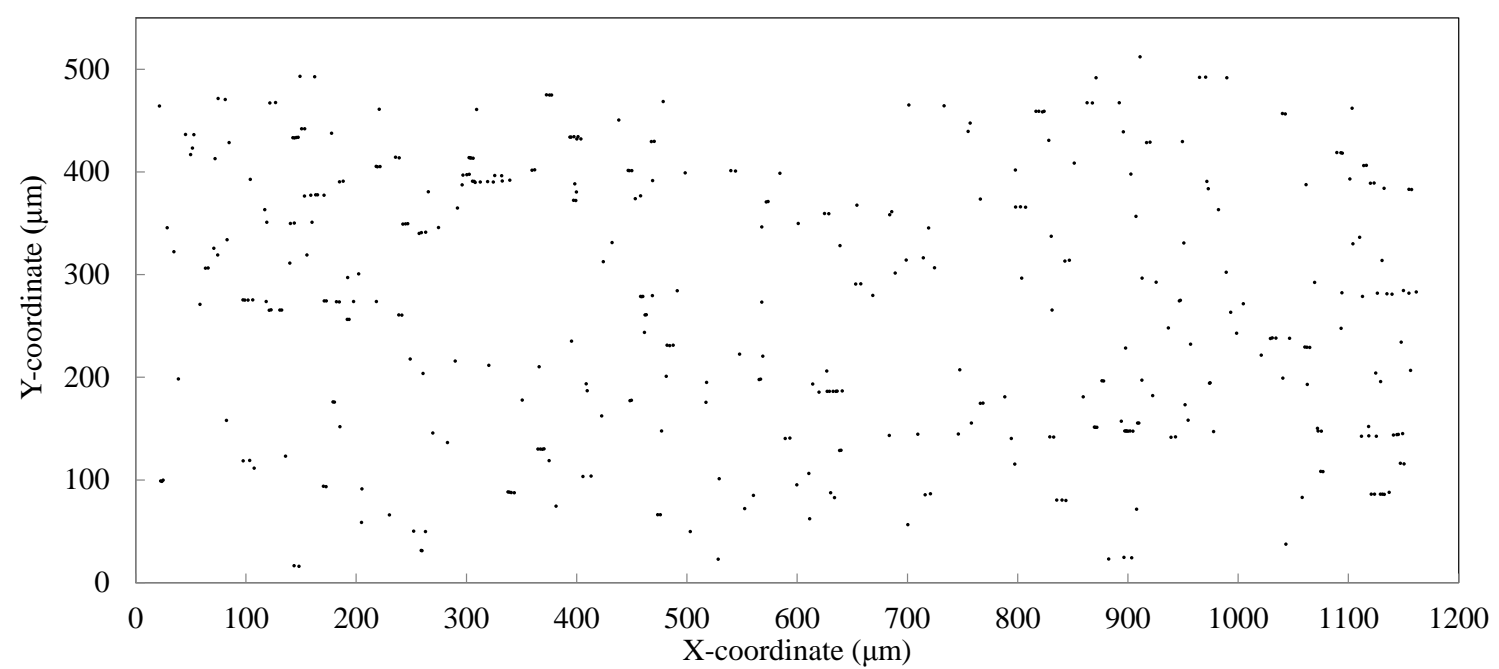

(b)

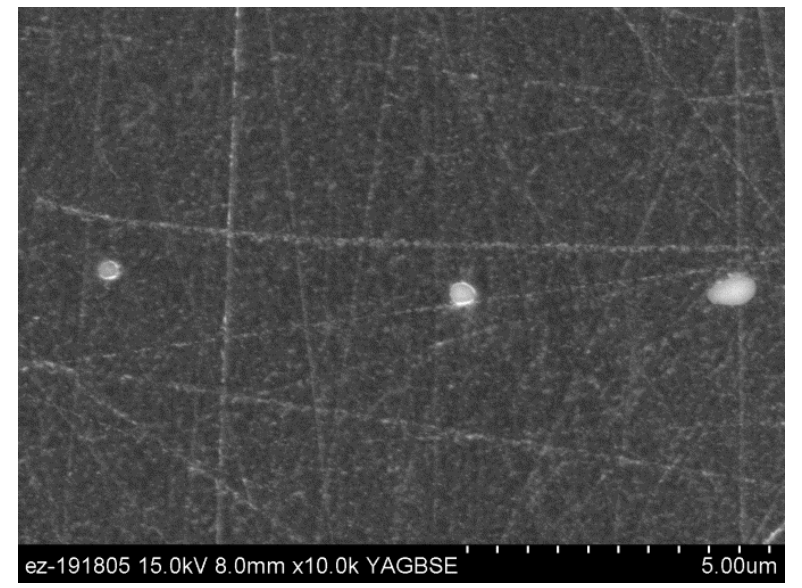

(c)

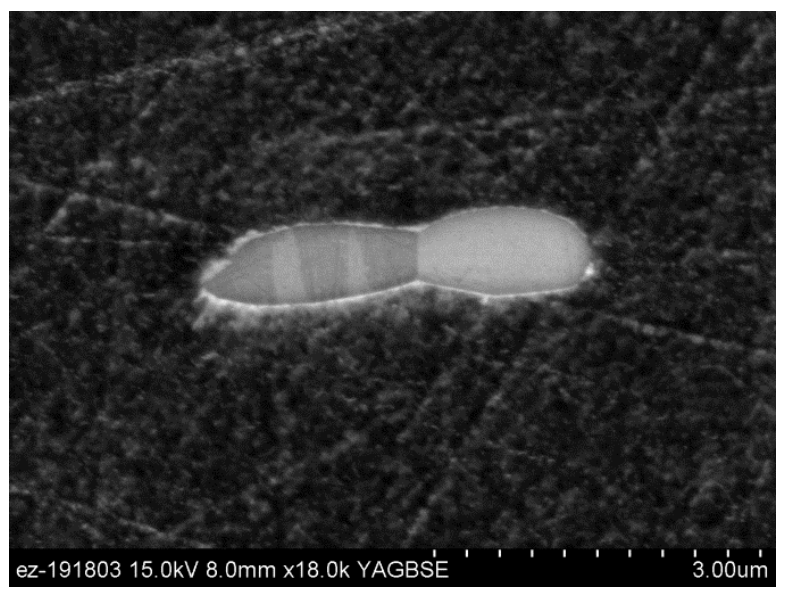

(d)

Fig. 8. Sample aged $500 \mathrm{~h}$ at $1500{ }^{\circ} \mathrm{C}$ - longitudinal section. (a) SEM montage (note: the resolution of this montage has been reduced compared to the original used in the data analysis) and (b) digitized precipitate locations corresponding to the SEM montage in (a). (c) and (d) are higher magnification BSE SEM images showing in (c) three relatively small precipitates aligned along the rolling direction and (d) a single relatively large precipitate elongated in the rolling direction. The rolling direction is along the horizontal of all figures. 


\subsubsection{Precipitate Size Analysis}

The average precipitate size was measured from SEM micrographs for each orientation of each condition and is presented in tabular form in Table 3. Each observed precipitate was approximated as an ellipse and the major and minor ellipse axis lengths are reported in Table 3 along with the 95\% confidence interval of the averages. The measured average precipitate sizes will be different than the actual values due to several factors. Since the micrographs are obtained from sections that cut through ellipsoidal precipitates in random locations [10], the measured major and minor axes from 2-dimensional sections will differ from the actual major and minor ellipse lengths. Furthermore, the precipitate morphologies are clearly influenced by the processing. For instance, qualitatively, many precipitates appeared to be elongated towards the rolling direction. Furthermore, the average major and minor ellipse axis lengths of the precipitates measured from the rolling surface of the as-recrystallized condition are larger than those measured on the longitudinal and transverse sections of the as-recrystallized condition, suggesting that the precipitates may have been "flattened" to some degree during the rolling. Therefore, precipitate size measurements from the longitudinal section, transverse section, and rolling surface may result in different values for a single heat treatment condition.

Table 3. Average Major and Minor Ellipse Axis Lengths for the L, S and R Surfaces of the As-Recrystallized and Aged Samples

\begin{tabular}{|c|c|c|c|c|c|c|c|}
\hline \multirow{3}{*}{$\begin{array}{c}\text { Heat } \\
\text { Treatment } \\
\text { Temp. }\left({ }^{\circ} \mathrm{C}\right)\end{array}$} & \multirow{3}{*}{$\begin{array}{c}\text { Heat } \\
\text { Treatment } \\
\text { Time (h) }\end{array}$} & \multicolumn{6}{|c|}{ Major Axis Length } \\
\hline & & \multicolumn{2}{|c|}{ L surface } & \multicolumn{2}{|c|}{ S surface } & \multicolumn{2}{|c|}{ R surface } \\
\hline & & $\begin{array}{c}\text { Length } \\
(\mu \mathrm{m})\end{array}$ & $\begin{array}{l}\text { 95\% Conf. } \\
\text { Int. }( \pm \mu \mathrm{m})\end{array}$ & $\begin{array}{c}\text { Length } \\
(\mu \mathrm{m})\end{array}$ & $\begin{array}{c}95 \% \\
\text { Conf. Int. } \\
( \pm \mu \mathrm{m})\end{array}$ & $\begin{array}{c}\text { Length } \\
(\mu \mathrm{m})\end{array}$ & $\begin{array}{c}95 \% \\
\text { Conf. Int. } \\
( \pm \mu \mathrm{m})\end{array}$ \\
\hline $\begin{array}{c}\text { As- } \\
\text { recrystallized }\end{array}$ & $\mathrm{n} / \mathrm{a}$ & 0.8 & 0.15 & 1.0 & 0.19 & 2.3 & 0.31 \\
\hline \multirow{3}{*}{1300} & 2000 & 1.2 & 0.17 & 0.9 & 0.15 & 1.1 & 0.18 \\
\hline & 5000 & 0.8 & 0.16 & 0.9 & 0.13 & 1.8 & 0.25 \\
\hline & 10,000 & 1.1 & 0.15 & 1.5 & 0.17 & 1.3 & 0.16 \\
\hline \multirow{3}{*}{1400} & 2000 & 1.1 & 0.24 & 1.4 & 0.15 & 1.4 & 0.19 \\
\hline & 5000 & 1.6 & 0.21 & 1.4 & 0.13 & 1.6 & 0.18 \\
\hline & 10,000 & 1.2 & 0.21 & 1.3 & 0.16 & 1.1 & 0.18 \\
\hline \multirow{3}{*}{1500} & 200 & 1.4 & 0.24 & 1.2 & 0.15 & 0.5 & 0.09 \\
\hline & 500 & 1.4 & 0.18 & 1.4 & 0.17 & 1.3 & 0.20 \\
\hline & 1000 & 1.5 & 0.18 & 1.4 & 0.16 & 1.0 & 0.16 \\
\hline \multirow{3}{*}{$\begin{array}{c}\text { Heat } \\
\text { Treatment } \\
\text { Temp. }\left({ }^{\circ} \mathrm{C}\right)\end{array}$} & \multirow{3}{*}{$\begin{array}{c}\text { Heat } \\
\text { Treatment } \\
\text { Time (h) }\end{array}$} & \multicolumn{6}{|c|}{ Minor Axis Length } \\
\hline & & \multicolumn{2}{|c|}{ L surface } & \multicolumn{2}{|c|}{ S surface } & \multicolumn{2}{|c|}{ R surface } \\
\hline & & $\begin{array}{l}\text { Length } \\
(\mu \mathrm{m})\end{array}$ & $\begin{array}{l}\text { 95\% Conf. } \\
\text { Int. }( \pm \mu \mathrm{m})\end{array}$ & $\begin{array}{l}\text { Length } \\
(\mu \mathrm{m})\end{array}$ & $\begin{array}{c}95 \% \\
\text { Conf. Int. } \\
( \pm \mu \mathrm{m})\end{array}$ & $\begin{array}{l}\text { Length } \\
(\mu \mathrm{m})\end{array}$ & $\begin{array}{l}\text { 95\% Conf. } \\
\text { Int. }( \pm \mu \mathrm{m})\end{array}$ \\
\hline $\begin{array}{c}\text { As- } \\
\text { recrystallized }\end{array}$ & $\mathrm{n} / \mathrm{a}$ & 0.4 & 0.07 & 0.5 & 0.11 & 1.3 & 0.18 \\
\hline \multirow{3}{*}{1300} & 2000 & 0.5 & 0.06 & 0.5 & 0.07 & 0.6 & 0.09 \\
\hline & 5000 & 0.5 & 0.13 & 0.9 & 0.10 & 1.2 & 0.16 \\
\hline & 10,000 & 0.7 & 0.09 & 0.9 & 0.11 & 0.8 & 0.10 \\
\hline \multirow{3}{*}{1400} & 2000 & 0.6 & 0.10 & 0.9 & 0.10 & 0.9 & 0.13 \\
\hline & 5000 & 0.9 & 0.10 & 1.0 & 0.10 & 1.1 & 0.10 \\
\hline & 10,000 & 0.7 & 0.10 & 0.8 & 0.11 & 0.8 & 0.12 \\
\hline \multirow{3}{*}{1500} & 200 & 0.6 & 0.09 & 0.7 & 0.09 & 0.4 & 0.05 \\
\hline & 500 & 0.7 & 0.06 & 0.9 & 0.11 & 0.9 & 0.12 \\
\hline & 1000 & 0.8 & 0.09 & 1.0 & 0.11 & 0.7 & 0.11 \\
\hline
\end{tabular}




\subsubsection{Precipitate Spacing Distribution}

Appendix B contains the precipitate locations, presented on graphs, corresponding to a single SEM montage for each orientation of each condition. Each graph has the same scale to facilitate comparisons between conditions. These graphs are provided to serve as inputs to models and/or to serve as comparisons to "sections" from 3-dimensional models of the microstructure of DOP-26. In order to obtain sufficient statistics on the inter-precipitate spacing, two montages each with an area of $\sim 0.5 \mathrm{~mm}^{2}$ were generated for each orientation of each condition. SEM analysis was performed at 500x magnification to obtain sufficient analysis area and high resolution images were captured in order to identify precipitates. The polishing procedure developed for these materials was able to facilitate identification of precipitates with sizes down to $200 \mathrm{~nm}$ using the aforementioned imaging conditions. The morphology of the precipitates and the tendency of precipitates to be oriented non-randomly will contribute to differences in the number density of individual orientations of a single heat treatment condition.

From the digitized locations of the precipitates, the nearest neighbor precipitate spacing distribution was characterized for each orientation of each condition. For this analysis, the first nearest neighbor precipitate distance at six angular intervals was calculated for every precipitate in a given montage. The six angular intervals used in the analysis were $>30$ to $90,>90$ to $150,>150$ to $210,>210$ to $270,>270$ to 330 , and $>330$ to 30 degrees. This resulted in a maximum of 6 possible nearest neighbor distances for each precipitate. In our coordinate system, the angular intervals are defined by the angle as measured counter clockwise from the horizontal of the micrographs (e.g., the RD for the longitudinal section and rolling surface and the LT direction for the transverse section). For some precipitates, such as those located near the edge of the sample or the edge of the montage, a nearest neighbor precipitate for one or more angular intervals was not present on the micrograph, and were not included in the analysis. For each angular interval, all nearest neighbor distances were then binned into $10 \mu \mathrm{m}$ intervals of increasing distance (e.g., 0-10 $\mu \mathrm{m}, 10-20 \mu \mathrm{m}, 20-30 \mu \mathrm{m}$, etc.) for a total of 25 intervals. Due to symmetry, the nearest neighbor distances calculated for all precipitates for the angular intervals $>150$ to 210 should, in general, be equivalent to those calculated from $>330$ to 30 degrees. In addition, the distribution of nearest neighbor precipitates in the angular intervals of $>30$ to $90,>90$ to 150, $>210$ to 270, and $>270$ to 330 should also be similar to one another due to symmetry. Consequently, two frequency distribution histograms of nearest neighbor precipitate distances for each orientation of each condition are presented in Appendix C. The first frequency distribution histogram is for angular intervals of $>150$ to 210 and $>330$ to 30 degrees and the second frequency distribution histogram is for angular intervals of $>30$ to 90 , $>90$ to $150,>210$ to 270 , and $>270$ to 330 . The angular intervals from $>150$ to 210 and $>330$ to 30 degrees contain a relatively high frequency of nearest neighbor precipitate distances from $0-10 \mu \mathrm{m}$ for the longitudinal sections and the rolling surfaces, owing to the precipitate stringers observed on these surfaces aligned along the RD. On the transverse section, a slightly higher frequency of nearest neighbor distances from $0-10 \mu \mathrm{m}$ was noted for the angular intervals of $>150$ to 210 and $>330$ to 30 degrees compared to the other angular intervals. 


\section{CONCLUSIONS}

A study has been initiated to characterize the effect of long term aging on grain growth and precipitation behavior in DOP-26. Samples of DOP-26 were aged at 1300,1400 , and $1500{ }^{\circ} \mathrm{C}$ for times ranging from 50 to 10,000 h. Grain size measurements (vertical and horizontal mean linear intercept and horizontal and vertical projection) were made on the longitudinal, transverse, and rolling surfaces after the long-term aging treatments. The size and spacing of the Th enriched precipitates in this study were determined as a function of aging time and temperature using scanning electron microscopy. The results obtained by this study are intended to provide input to grain growth models of DOP-26.

\section{FUTURE WORK}

The following items have been identified as potential areas for future work:

- Relatively large grains were observed to be preferentially located near the surface in some samples, particularly those aged for longer times and at higher temperatures. The cause of this behavior in the present work is not clear at this time but could be important in understanding the mechanisms of grain growth during long-term aging and to enabling improved modeling capability. In previous work, aging in a low partial pressure oxygen atmosphere has been reported to cause similar abnormally large grain growth on the surface of DOP-26 samples, due to depletion of Th at the boundaries of near surface grains and a reduction in size of IrTh precipitates [9]. However, it is not clear if oxygen, when present at significantly lower levels (during aging) like in the current study, might affect grain growth behavior during aging at much longer times (such as those times incorporated in this study).

Therefore, an investigation into the factor(s) which may cause abnormally large grain growth in near surface grains during long-term aging, and any effect it may have on precipitate behavior, is suggested for further investigation.

- Heat to heat variations in bulk Th content are known to occur in DOP-26 (within the 30-90 wppm specification limit). However, it is not well understood how significantly these variations in Th content influence the initial precipitate size and distribution, the evolution of precipitate size and distribution during aging, and ultimately, grain growth. An improved understanding of these factors may enhance grain growth predictive capabilities as well as provide insight into the mechanisms that may cause variations in grain growth rates observed in different heats of DOP-26. Material from three different heats of DOP-26, encompassing a range of Th content as measured by glow discharge mass spectroscopy, have been selected to further understand these factors. Methods developed in the present work to quantitatively characterize precipitate size and distribution can be applied to these different heats of DOP-26 with varying Th contents.

\section{REFERENCES}

[1] C. T. Liu and H. Inouye, Study of Iridium and Iridium-Tungsten Alloys for Space Radioisotopic Heat Sources, Oak Ridge National Laboratory, Oak Ridge, TN, 1976.

[2] C. T. Liu and H. Inouye, Development and Characterization of an Improved Ir-0.3\% W Alloy for Space Radioisotopic Heat Sources, Oak Ridge National Laboratory, Oak Ridge, TN, 1977.

[3] L. Heatherly and E. P. George, Grain-Boundary Segregation of Impurites in Iridium and Effects on Mechanical Properties, Acta Materialia, vol. 49, pp. 289-298, 2001.

[4] C. T. Liu, H. Inouye and A. C. Schaffhauser, Effect of Thorium Additions on Metallurgical and Mechanical Proeprties of Ir-0.3 pct W Alloys, Metallurgical Transactions A, vol. 12, pp. 993-1002, 1981. 
[5] J. R. Morris, F. W. Averill and V. R. Cooper, Theoretical Studies of $\operatorname{Ir}_{5} T h$ and $\operatorname{Ir}_{5} C e$ Nanoscale Precipitates in Ir, Philosophical Magazine, vol. 94, pp. 991-1000, 2014.

[6] C. G. McKamey, E. H. Lee, G. B. Ulrich, J. L. Wright and E. P. George, Grain Growth Behavior of DOP-26 Iridium Clad Vent Set Cups Used in Radioisotope Thermoelectric Generators, Oak Ridge National Laboratory, 2002.

[7] D. E. Harasyn and A. C. Schaffhauser, Grain Growth in Ir-0.3 Pct W alloys, Metallurgical Transactions A, vol. 10, pp. 823-830, 1979.

[8] C. G. McKamey, A. N. Gubbi, Y. Lin and E. P. George, Grain-Growth Behavior and Low-Pressure Oxygen Compatibility of an Ir-0.3 wt.\% W alloy, Journal of Alloys and Compounds, vol. 244, pp. 175-183, 1996.

[9] C. G. McKamey, A. N. Gubbi, Y. Lin, J. W. Cohron, E. H. Lee and E. P. George, Grain Growth Behavior and High-Temperature High-Strain-Rate Ductility of Iridium Alloy DOP-26, Oak Ridge National Laboratory, 1998.

[10] R. T. DeHoff, The Determination of the Size Distribution of Ellipsoidal Particles from Measuremtnes Made on Random Plane Sections, Transactions of the Metallurgical Society of AIME, vol. 224, pp. 474-477, 1962. 
APPENDIX A. FREQUENCY HISTOGRAMS OF THE GRAIN SIZE 



\section{FREQUENCY HISTOGRAMS OF THE GRAIN SIZE}
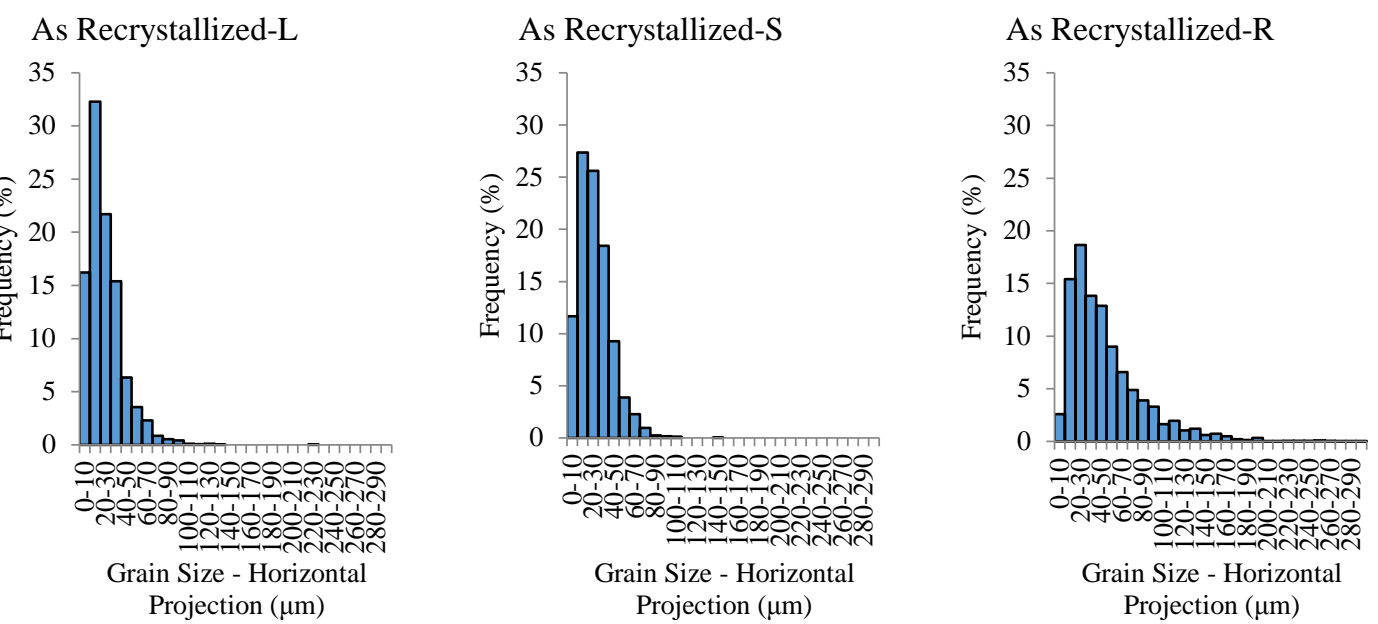

Fig. A1. Frequency histograms of the measured horizontal projection lengths for the $L, S$, and $R$ surfaces (left to right) for the as-recrystallized condition. 

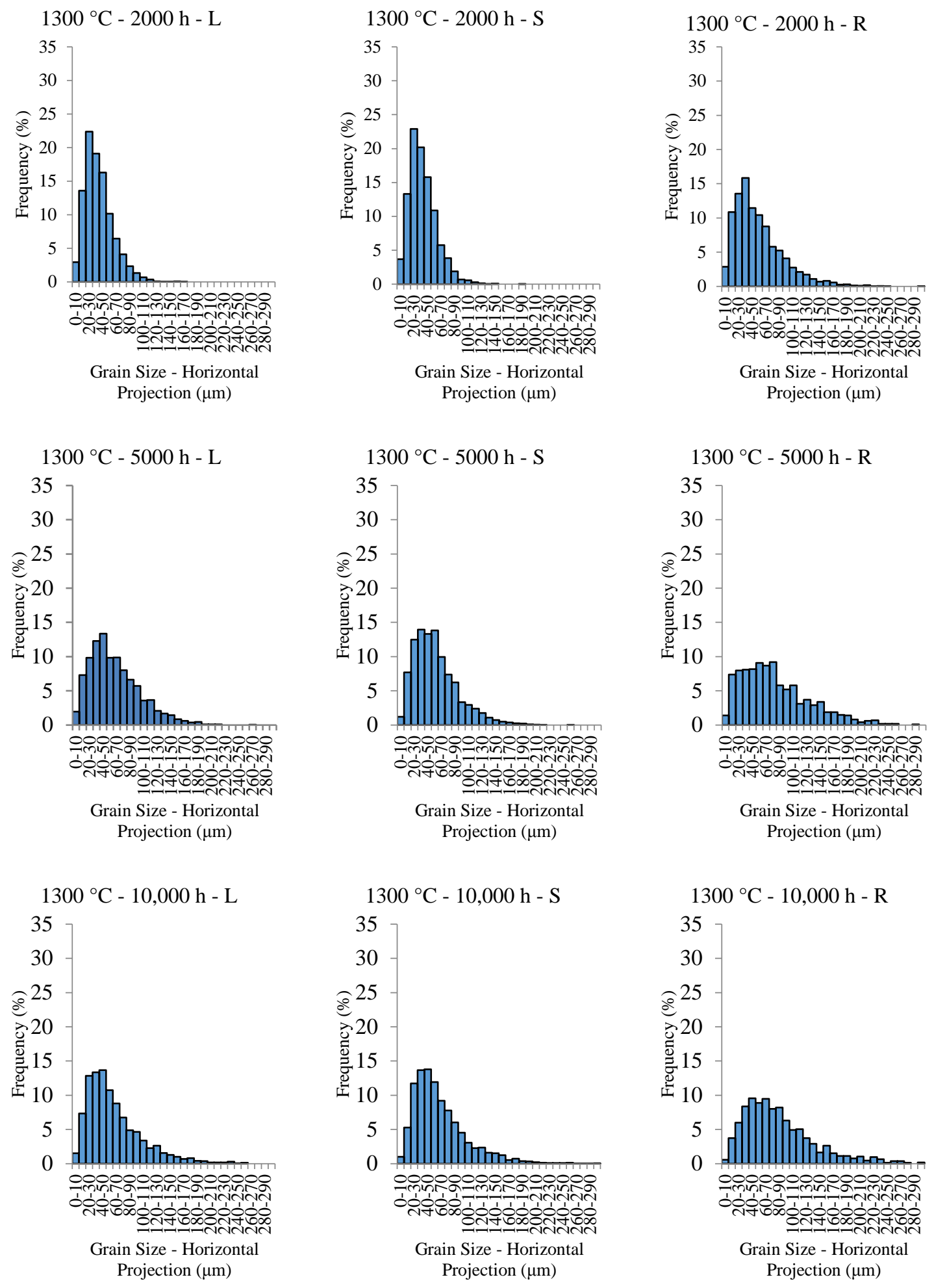

Fig. A2. Frequency histograms of the measured horizontal projection lengths for the $L, S$, and $R$ surfaces (left to right) after aging at $1300{ }^{\circ} \mathrm{C}$ for $2000 \mathrm{~h}$ (top), $5000 \mathrm{~h}$ (middle), and 10,000 h (bottom). 

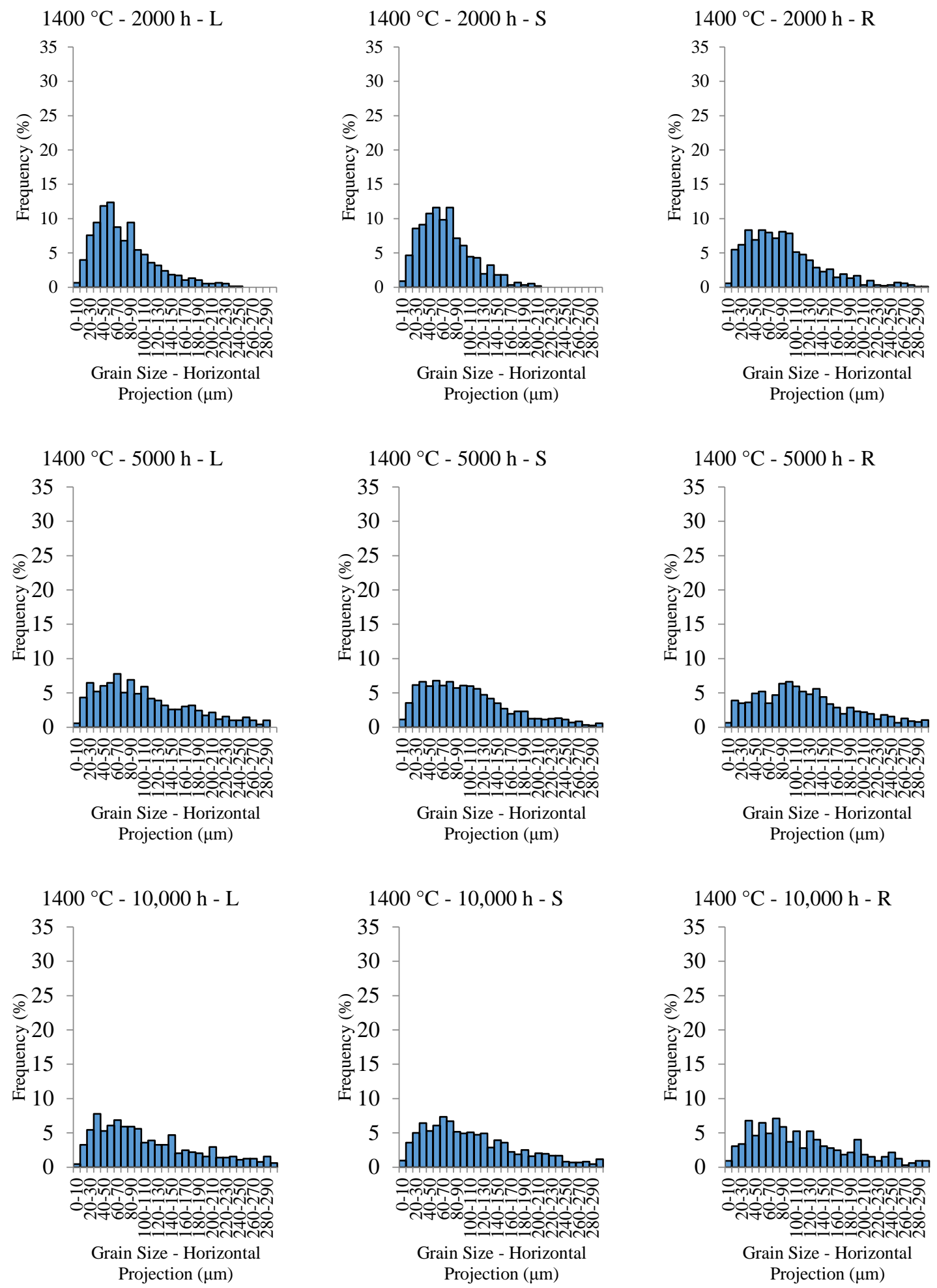

Fig. A3. Frequency histograms of the measured horizontal projection lengths for the $L, S$, and $R$ surfaces (left to right) after aging at $1400{ }^{\circ} \mathrm{C}$ for $2000 \mathrm{~h}$ (top), $5000 \mathrm{~h}$ (middle), and 10,000 h (bottom). 

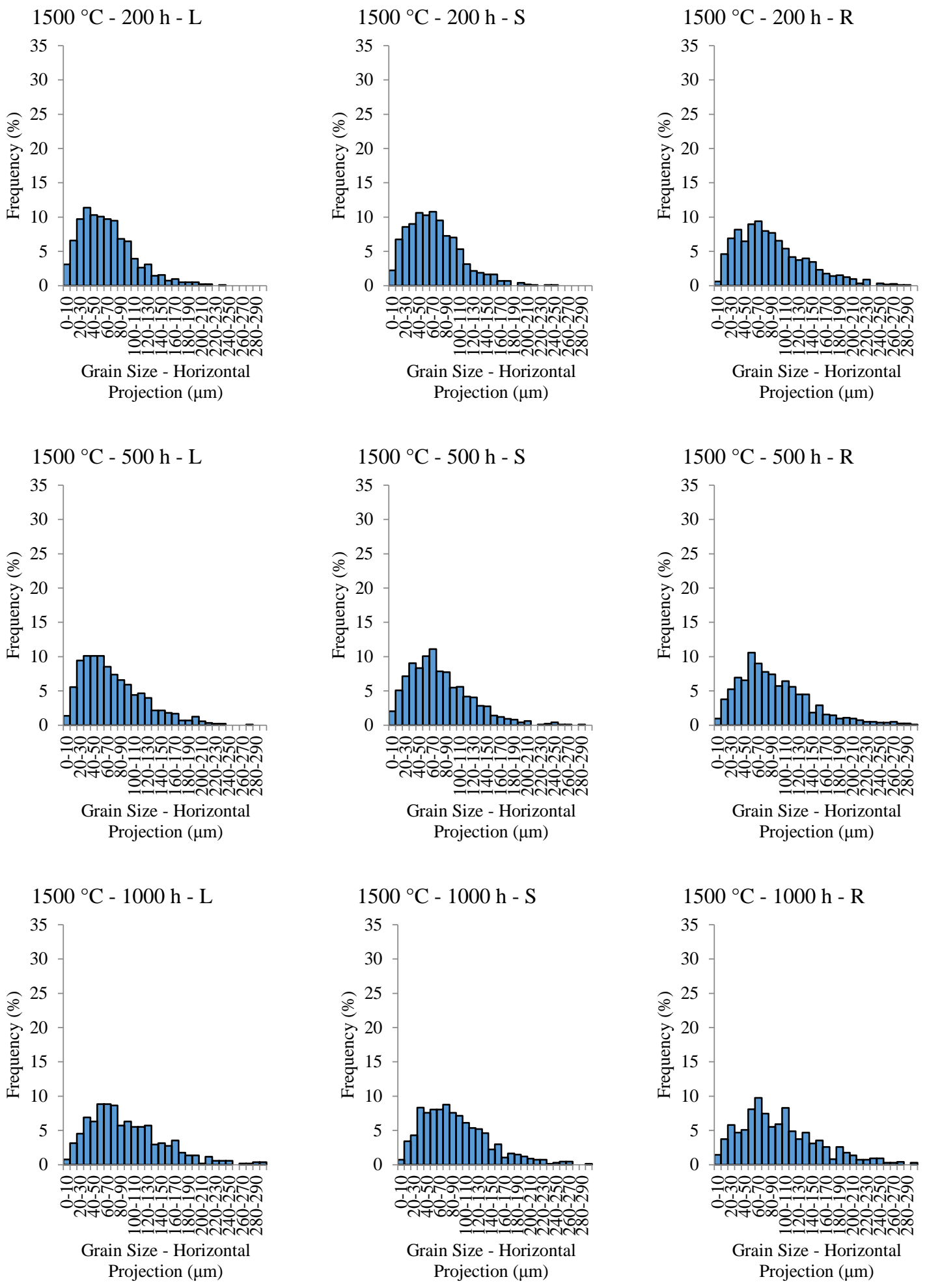

Fig. A4. Frequency histograms of the measured horizontal projection lengths for the $L, S$, and $R$ surfaces (left to right) after aging at $1500{ }^{\circ} \mathrm{C}$ for $200 \mathrm{~h}$ (top), $500 \mathrm{~h}$ (middle), and $1000 \mathrm{~h}$ (bottom). 

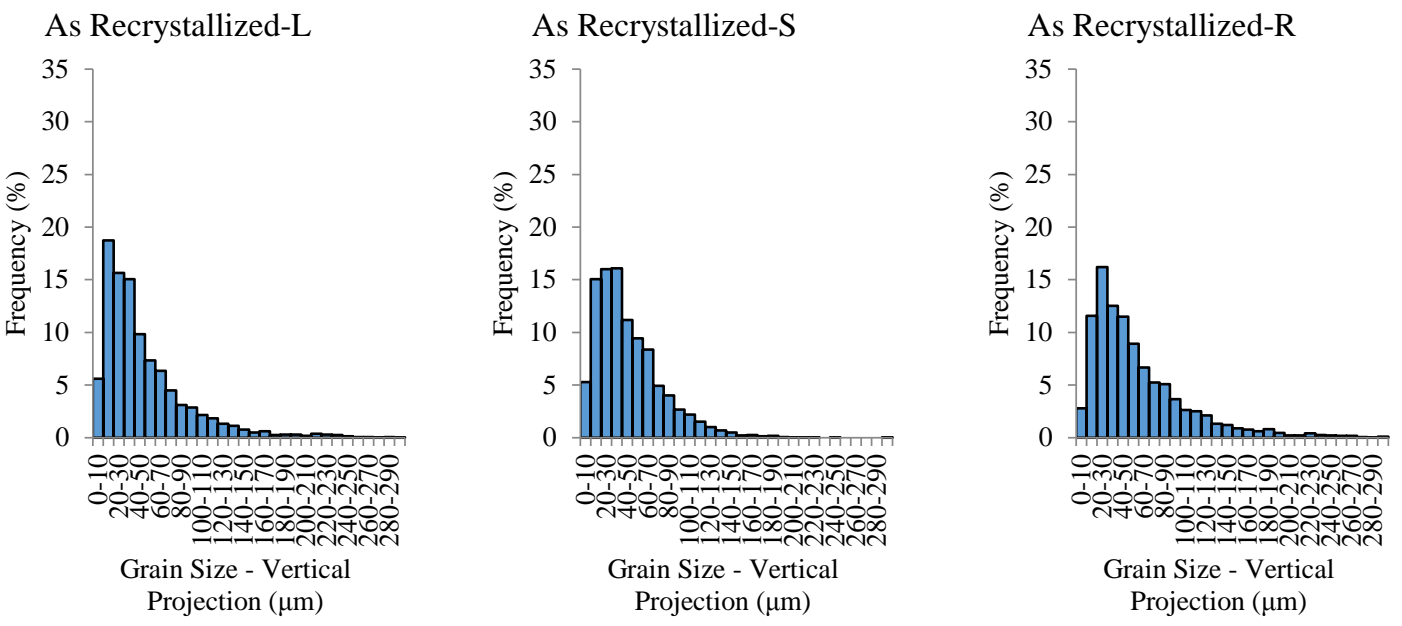

Fig. A5. Frequency histograms of the measured vertical projection lengths for the $L, S$, and $R$ surfaces (left to right) of the as-recrystallized condition. 

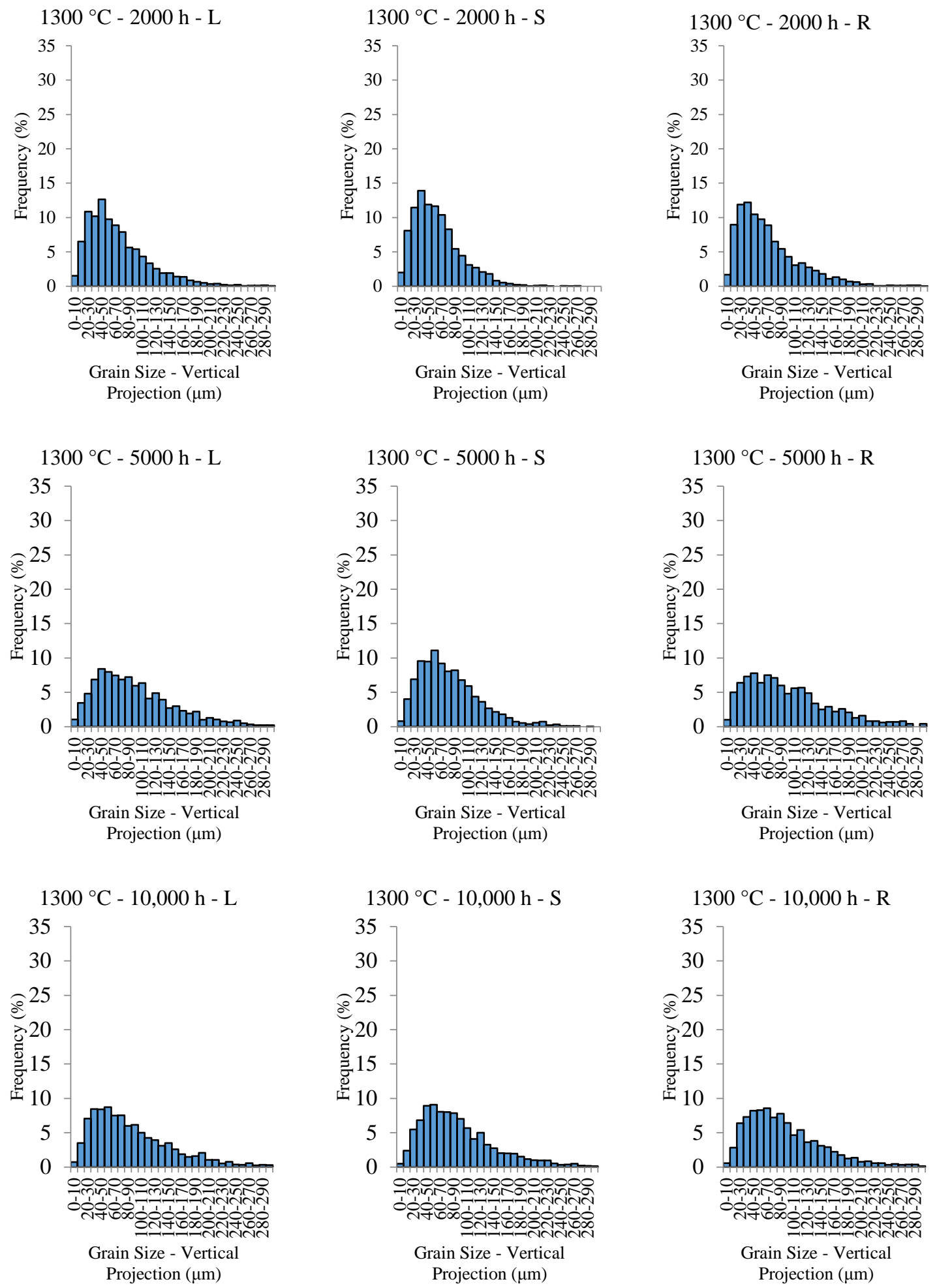

Fig. A6. Frequency histograms of the measured vertical projection lengths for the $L, S$, and $R$ surfaces (left to right) after aging at $1300{ }^{\circ} \mathrm{C}$ for $2000 \mathrm{~h}$ (top), $5000 \mathrm{~h}$ (middle), and 10,000 h (bottom). 

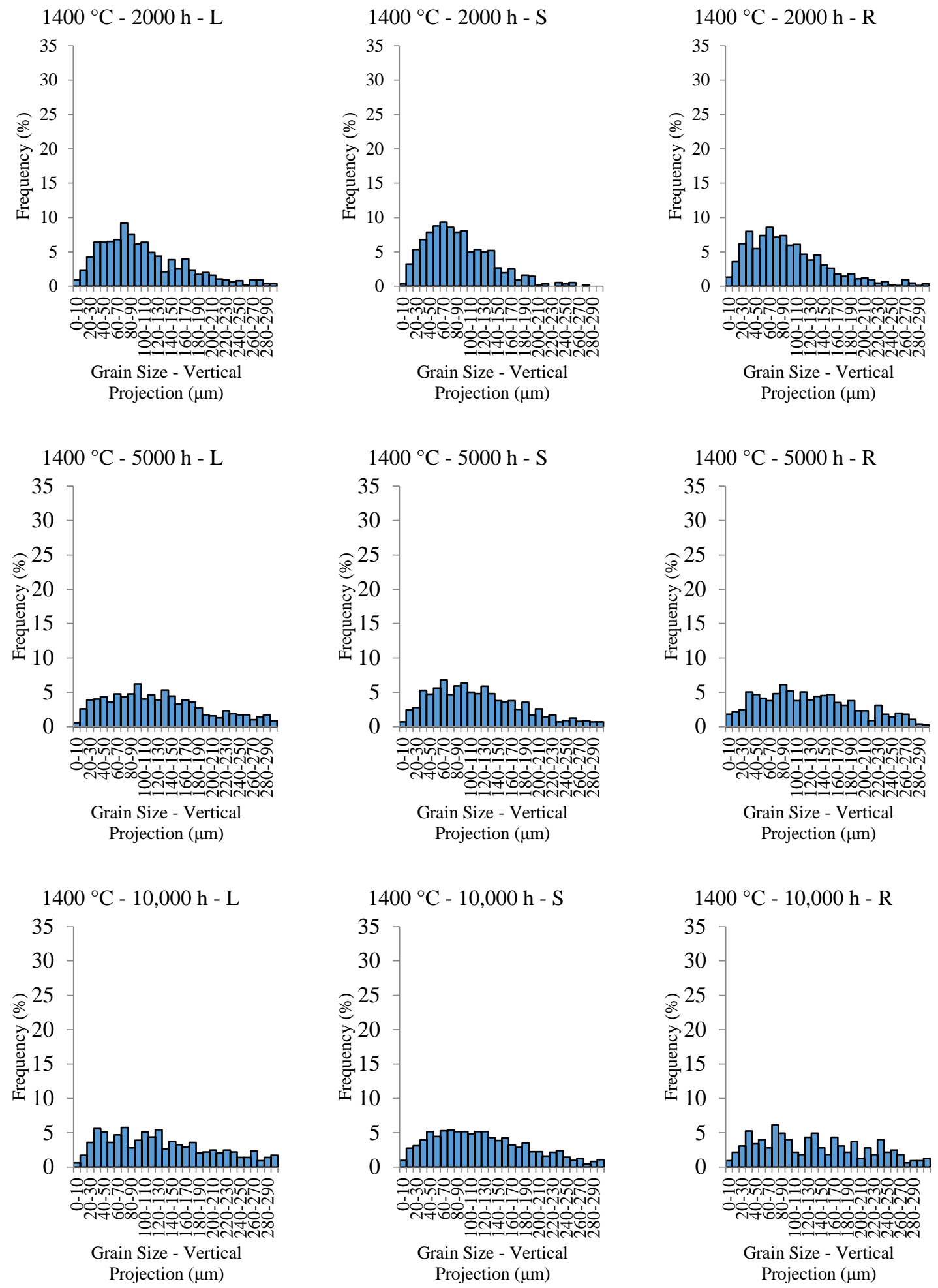

Fig. A7. Frequency histograms of the measured vertical projection lengths for the $L, S$, and $R$ surfaces (left to right) after aging at $1400{ }^{\circ} \mathrm{C}$ for $2000 \mathrm{~h}$ (top), $5000 \mathrm{~h}$ (middle), and 10,000 h (bottom). 

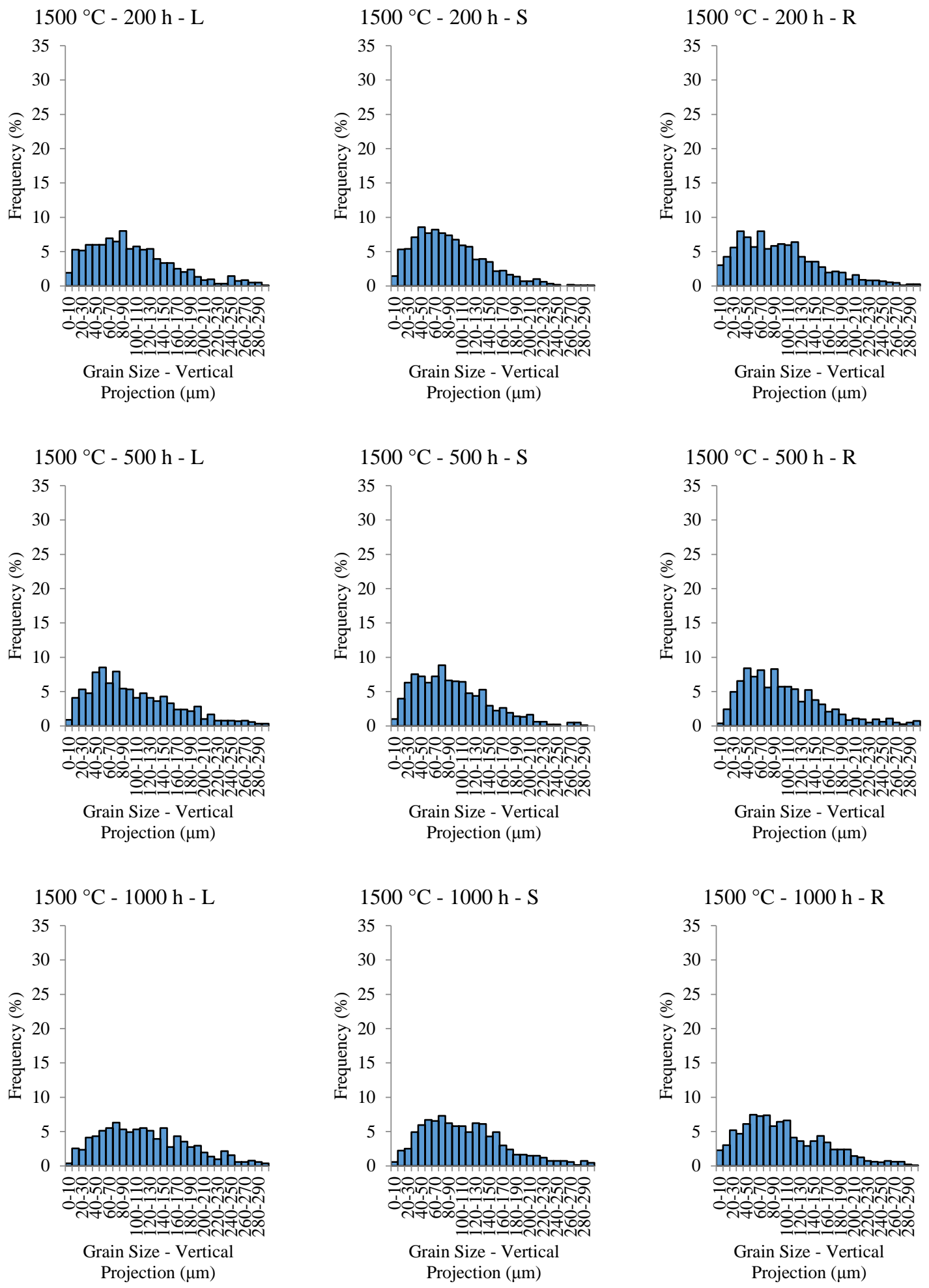

Fig. A8. Frequency histograms of the measured vertical projection lengths for the $L, S$, and $R$ surfaces (left to right) after aging at $1500{ }^{\circ} \mathrm{C}$ for $200 \mathrm{~h}$ (top), $500 \mathrm{~h}$ (middle), and $1000 \mathrm{~h}$ (bottom). 
APPENDIX B. GRAPHS OF THE TWO-DIMENSIONAL PRECIPITATE LOCATIONS 



\section{GRAPHS OF THE TWO-DIMENSIONAL PRECIPITATE LOCATIONS}

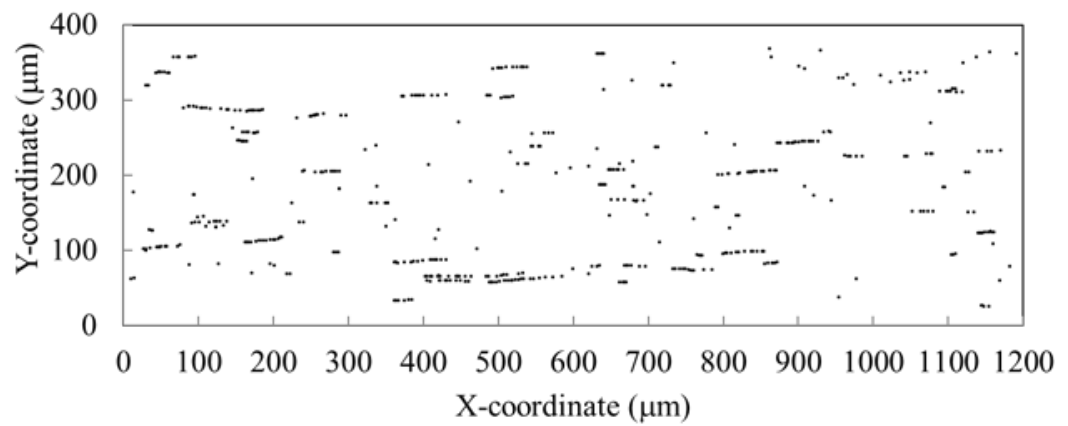

(a)

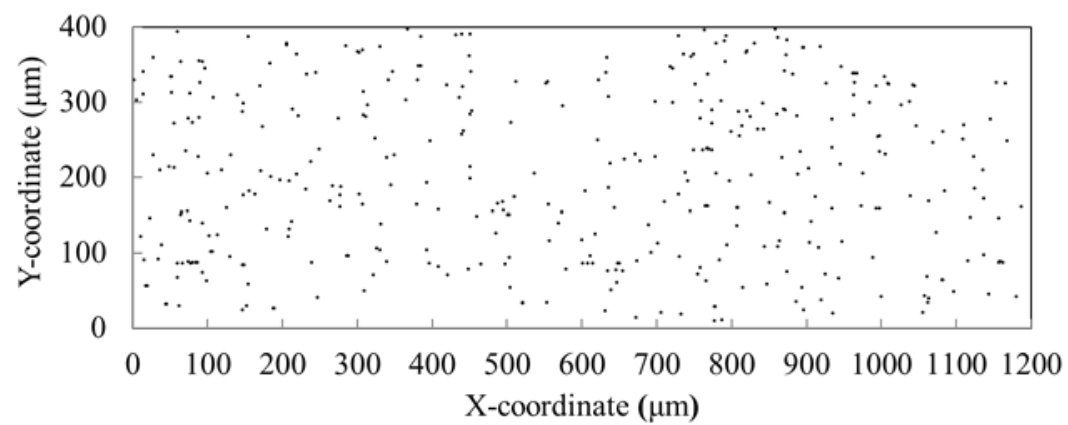

(b)

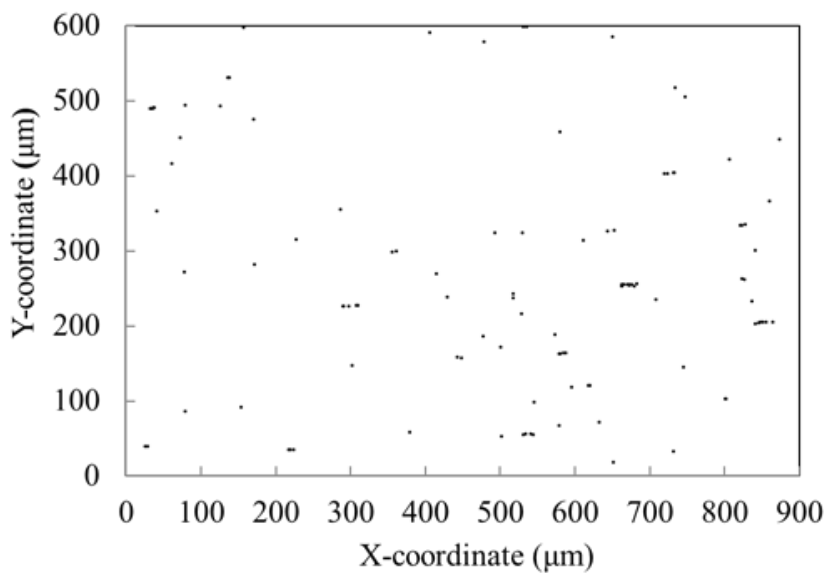

(c)

Fig. B1. As-recrystallized sample - digitized precipitate locations corresponding to the (a) longitudinal section, (b) transverse section, and (c) the rolling surface. The horizontal is approximately along the rolling direction in (a) and (c) and the long transverse direction in (b). The center of each dot represents the location of a single precipitate. 


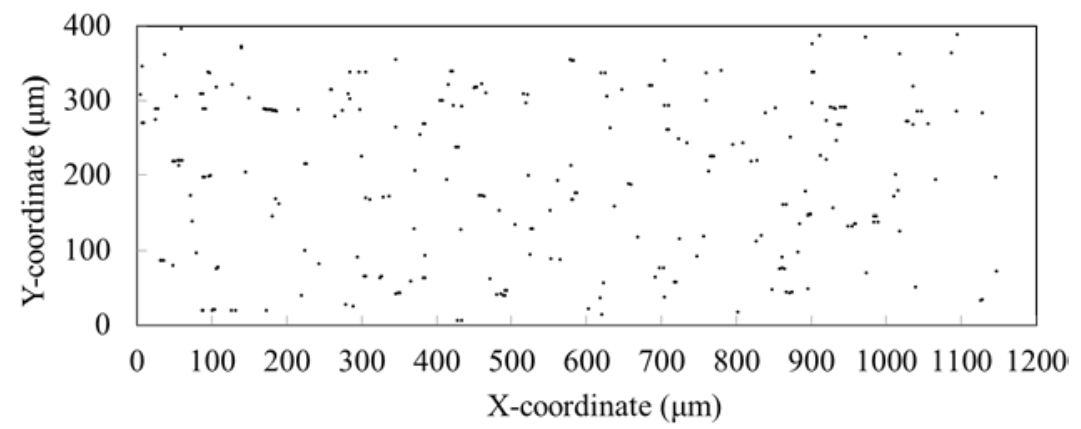

(a)

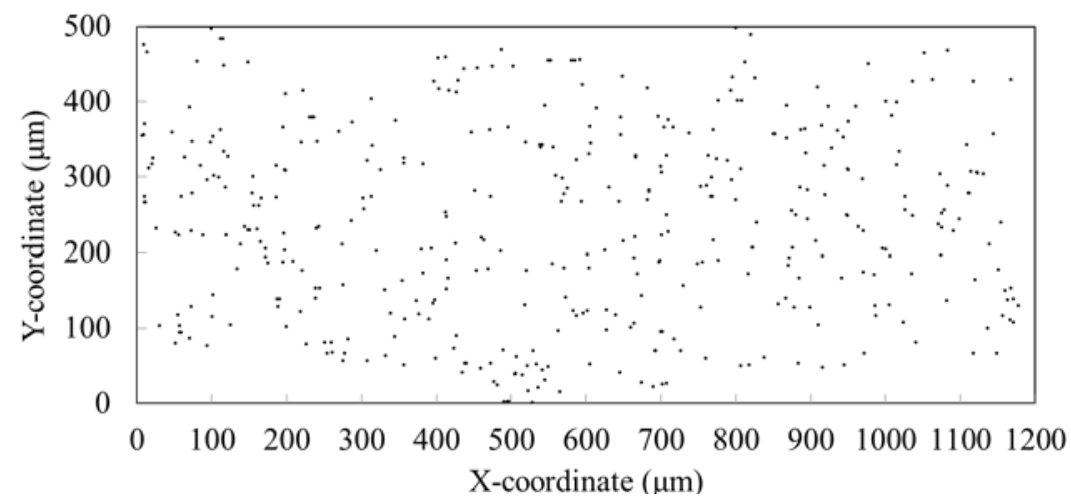

(b)

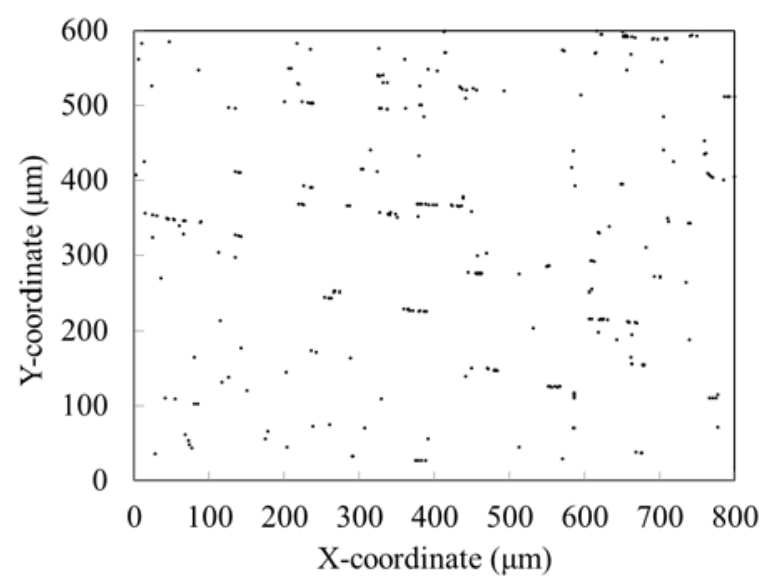

(c)

Fig. B2. Sample aged at $1300{ }^{\circ} \mathrm{C}$ for $2000 \mathrm{~h}$ - digitized precipitate locations corresponding to the (a) longitudinal section, (b) transverse section, and (c) the rolling surface. The horizontal is approximately along the rolling direction in (a) and (c) and the long transverse direction in (b). The center of each dot represents the location of a single precipitate. 


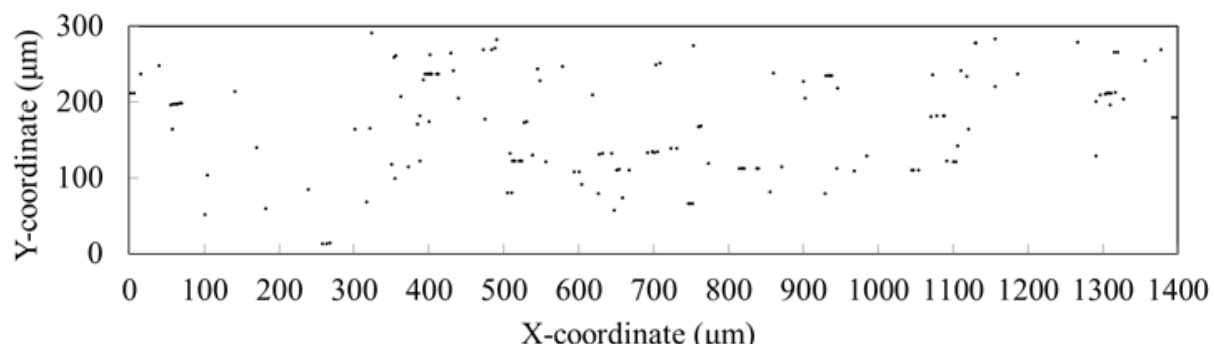

(a)

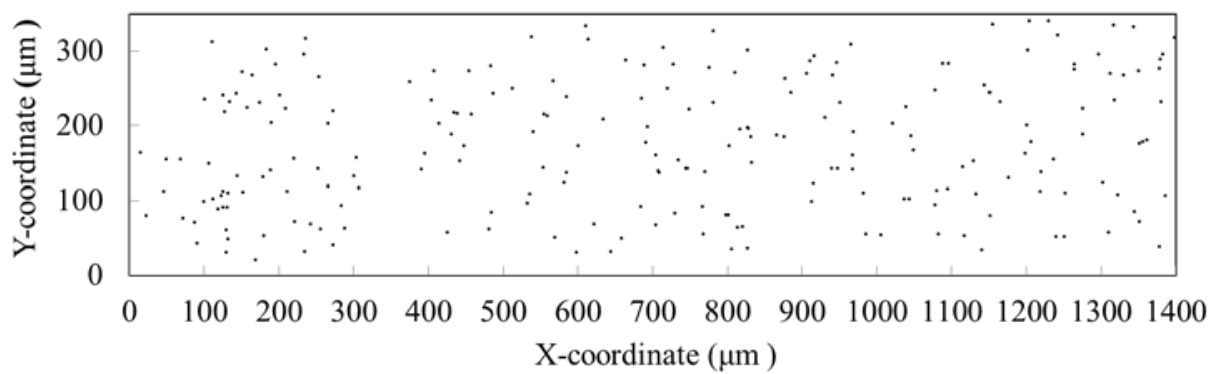

(b)

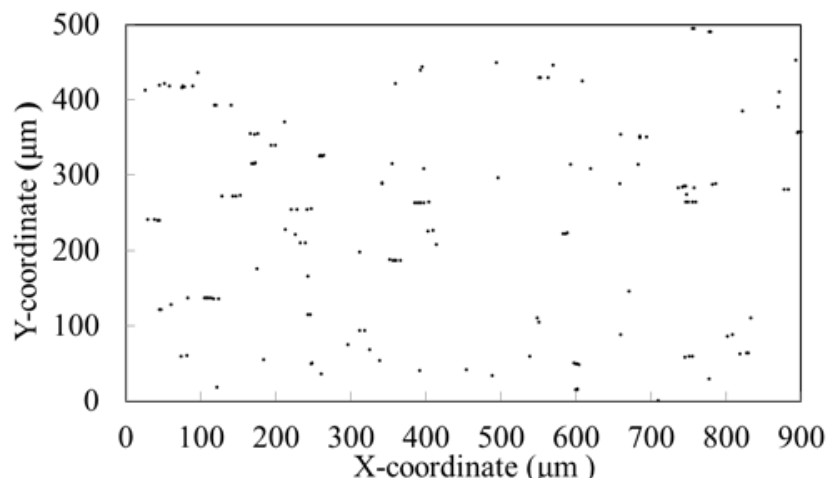

(c)

Fig. B3. Sample aged at $1300{ }^{\circ} \mathrm{C}$ for $5000 \mathrm{~h}$ - digitized precipitate locations corresponding to the (a) longitudinal section, (b) transverse section, and (c) the rolling surface. The horizontal is approximately along the rolling direction in (a) and (c) and the long transverse direction in (b). The center of each dot represents the location of a single precipitate. 


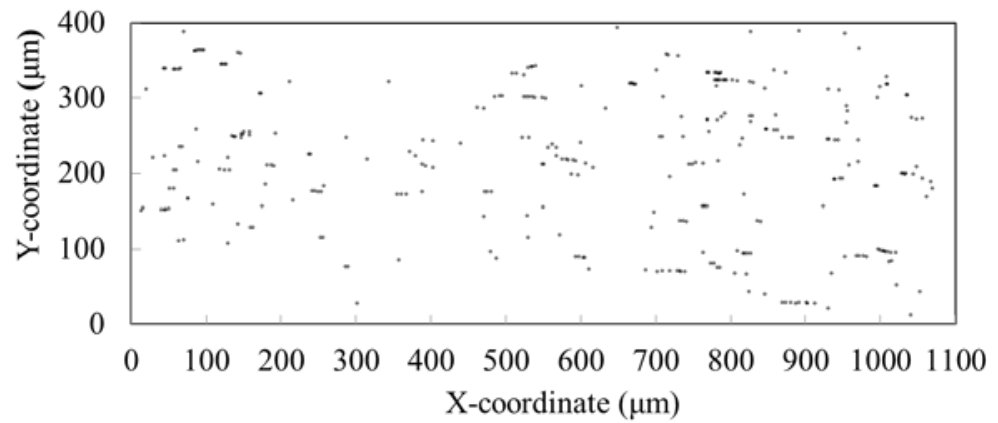

(a)

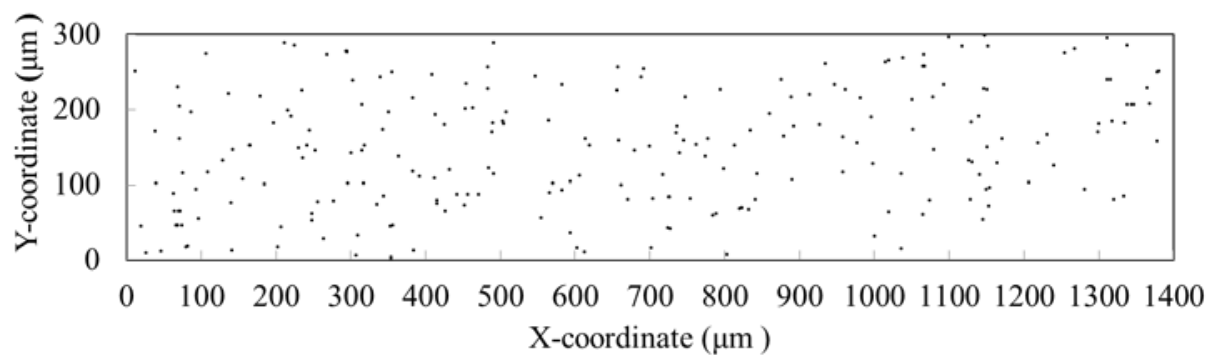

(b)

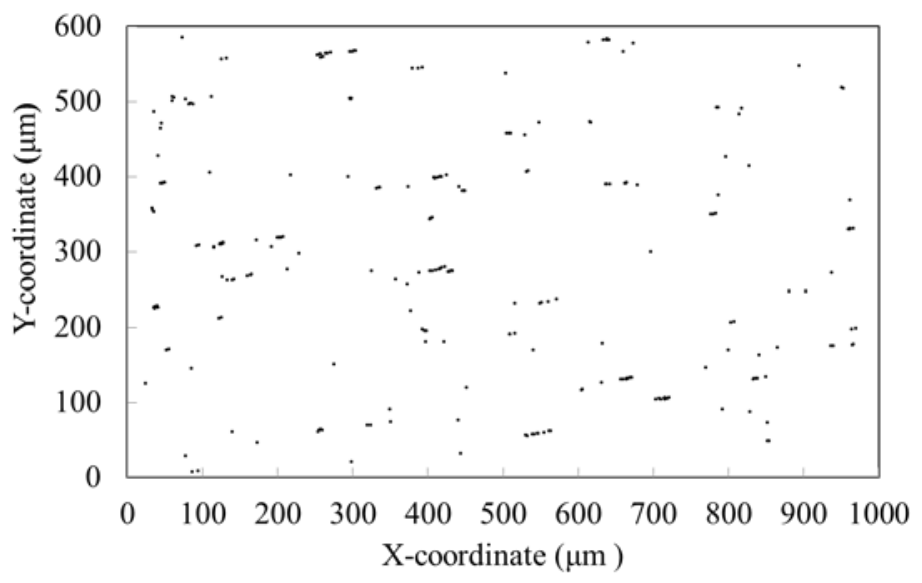

(c)

Fig. B4. Sample aged at $1300{ }^{\circ} \mathrm{C}$ for $10,000 \mathrm{~h}$ - digitized precipitate locations corresponding to the (a) longitudinal section, (b) transverse section, and (c) the rolling surface. The horizontal is approximately along the rolling direction in (a) and (c) and the long transverse direction in (b). The center of each dot represents the location of a single precipitate. 


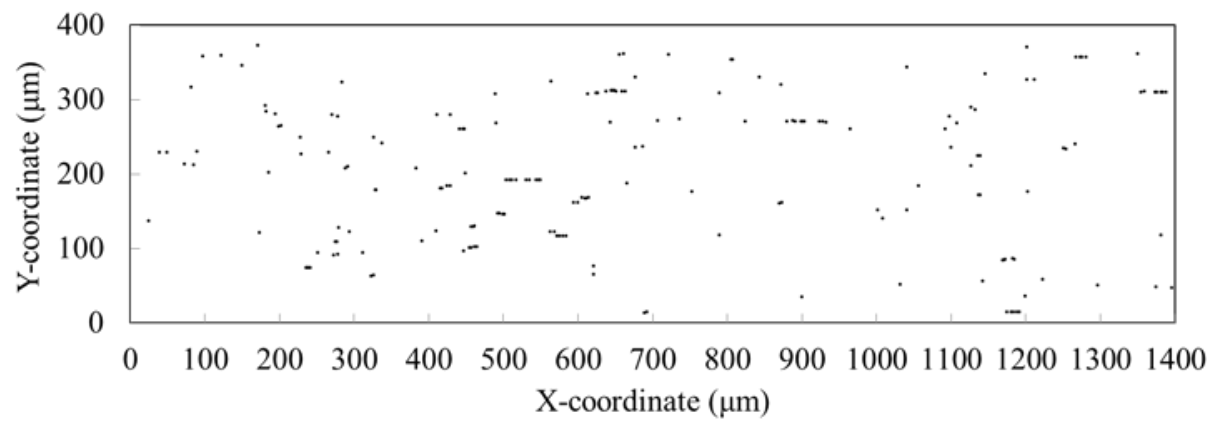

(a)

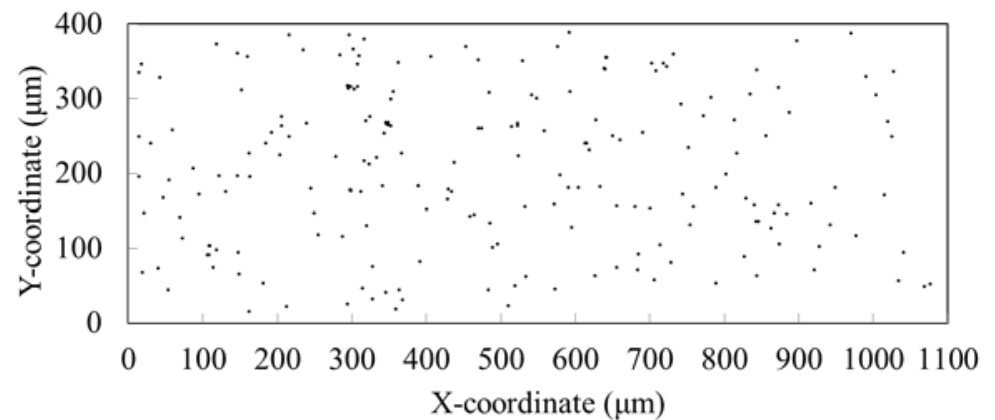

(b)

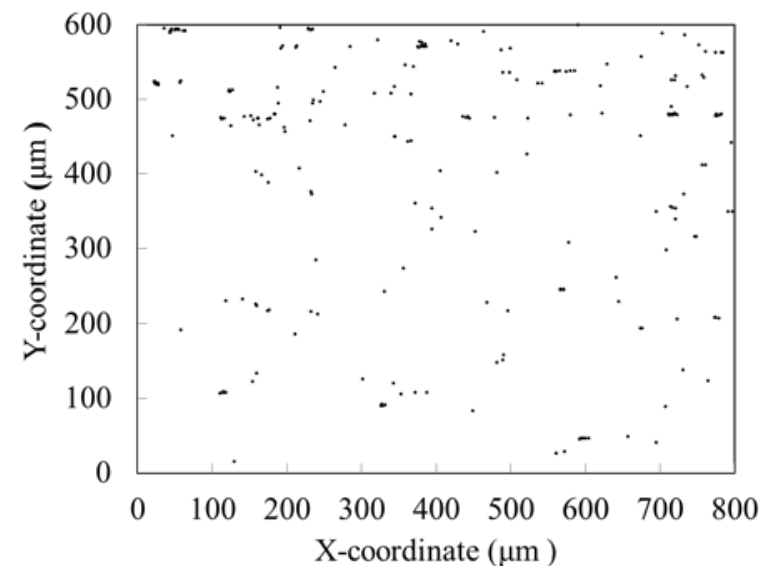

(c)

Fig. B5. Sample aged at $1400{ }^{\circ} \mathrm{C}$ for $2000 \mathrm{~h}$ - digitized precipitate locations corresponding to the (a) longitudinal section, (b) transverse section, and (c) the rolling surface. The horizontal is approximately along the rolling direction in (a) and (c) and the long transverse direction in (b). The center of each dot represents the location of a single precipitate. 


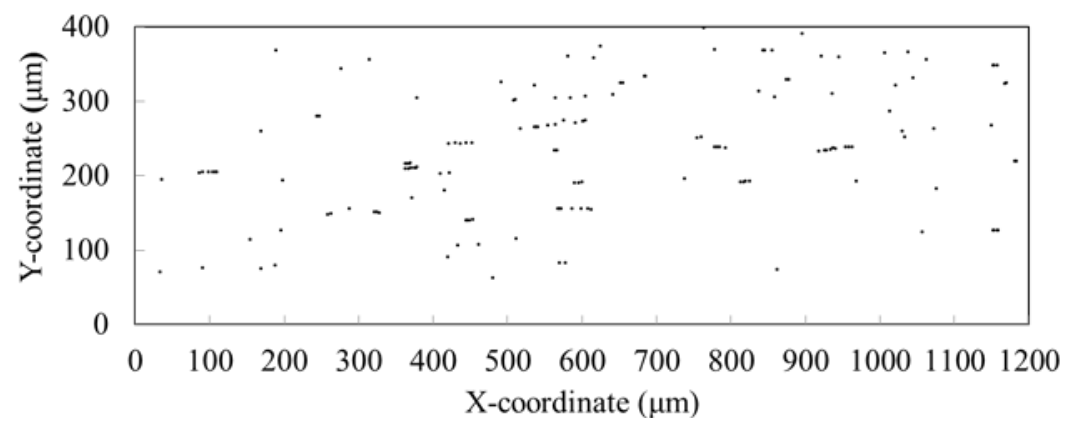

(a)

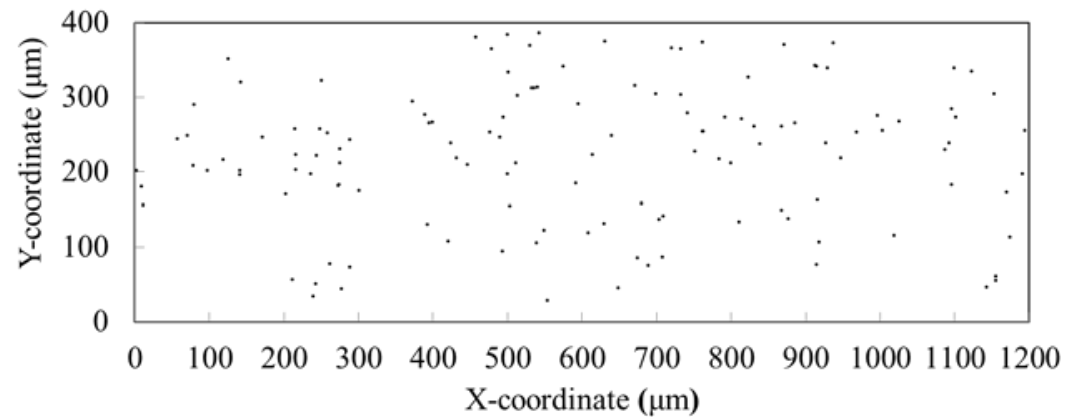

(b)

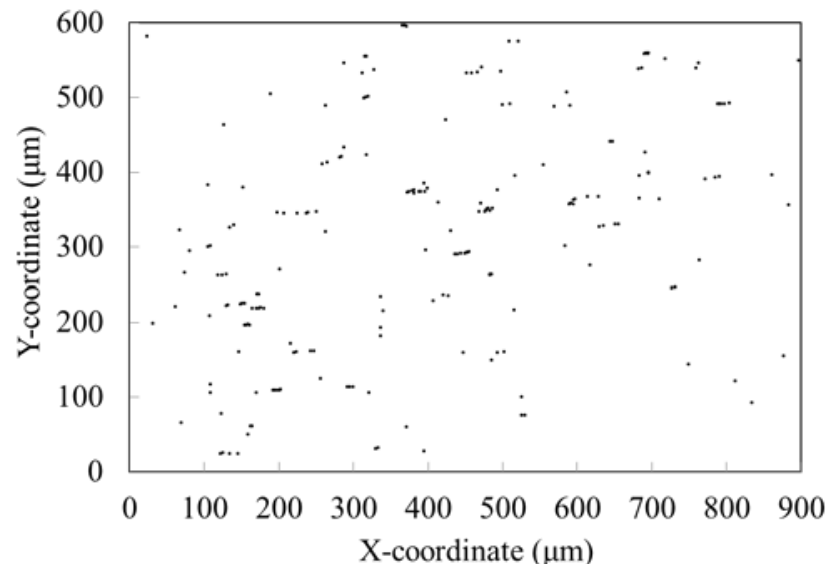

(c)

Fig. B6. Sample aged at $1400{ }^{\circ} \mathrm{C}$ for $5000 \mathrm{~h}$ - digitized precipitate locations corresponding to the (a) longitudinal section, (b) transverse section, and (c) the rolling surface. The horizontal is approximately along the rolling direction in (a) and (c) and the long transverse direction in (b). The center of each dot represents the location of a single precipitate. 


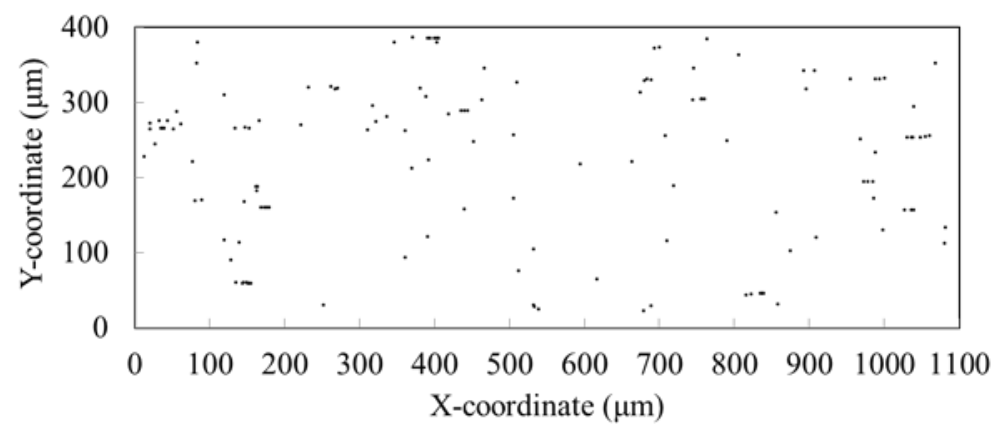

(a)

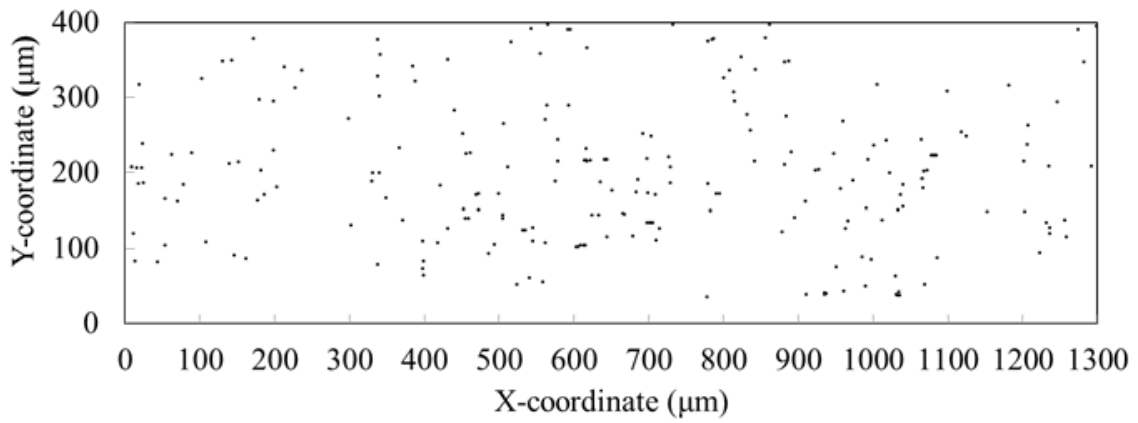

(b)

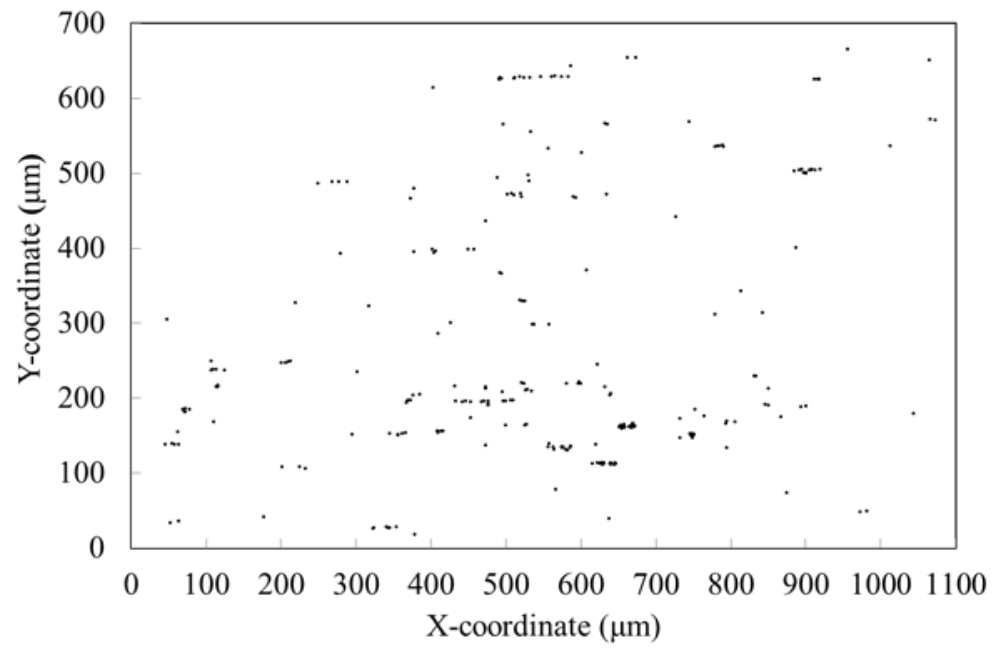

(c)

Fig. B7. Sample aged at $1400{ }^{\circ} \mathrm{C}$ for $10,000 \mathrm{~h}$ - digitized precipitate locations corresponding to the (a) longitudinal section, (b) transverse section, and (c) the rolling surface. The horizontal is approximately along the rolling direction in (a) and (c) and the long transverse direction in (b). The center of each dot represents the location of a single precipitate. 


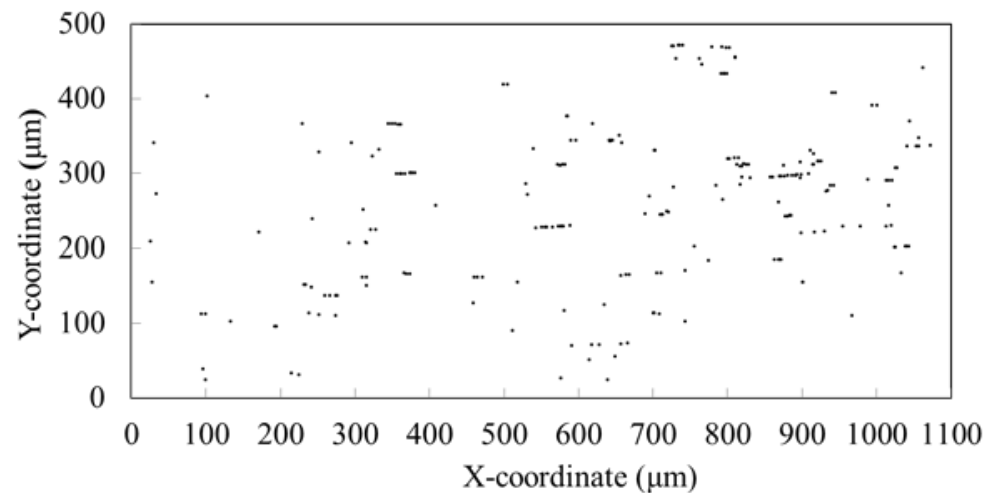

(a)

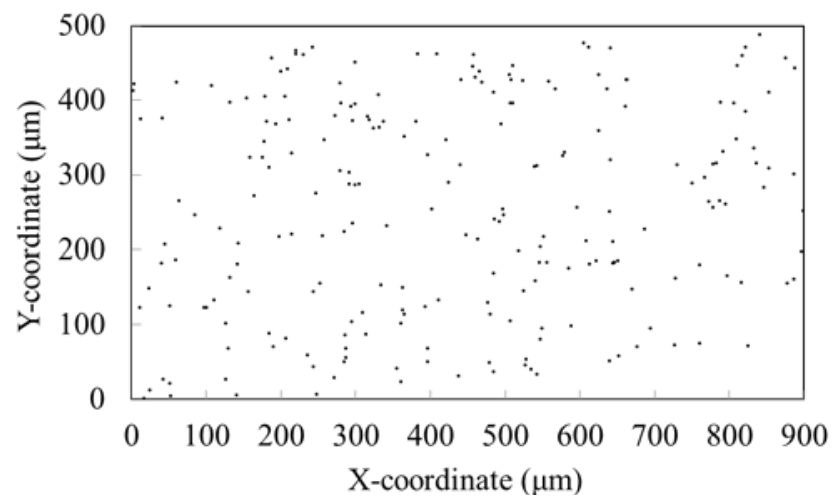

(b)

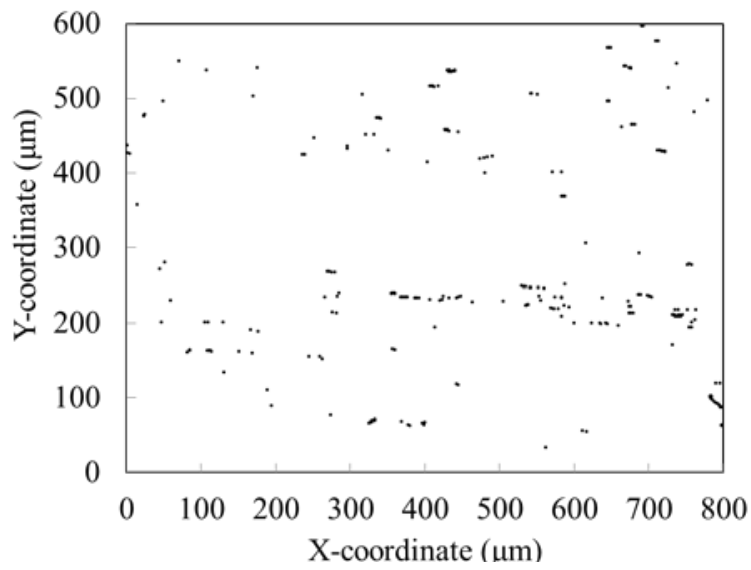

(c)

Fig. B8. Sample aged at $1500{ }^{\circ} \mathrm{C}$ for $200 \mathrm{~h}$ - digitized precipitate locations corresponding to the (a) longitudinal section, (b) transverse section, and (c) the rolling surface. The horizontal is approximately along the rolling direction in (a) and (c) and the long transverse direction in (b). The center of each dot represents the location of a single precipitate. 


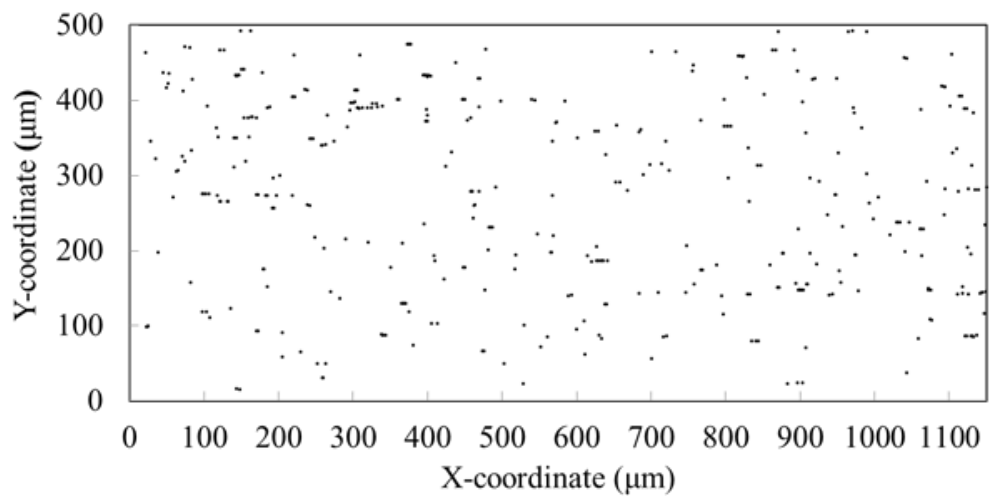

(a)

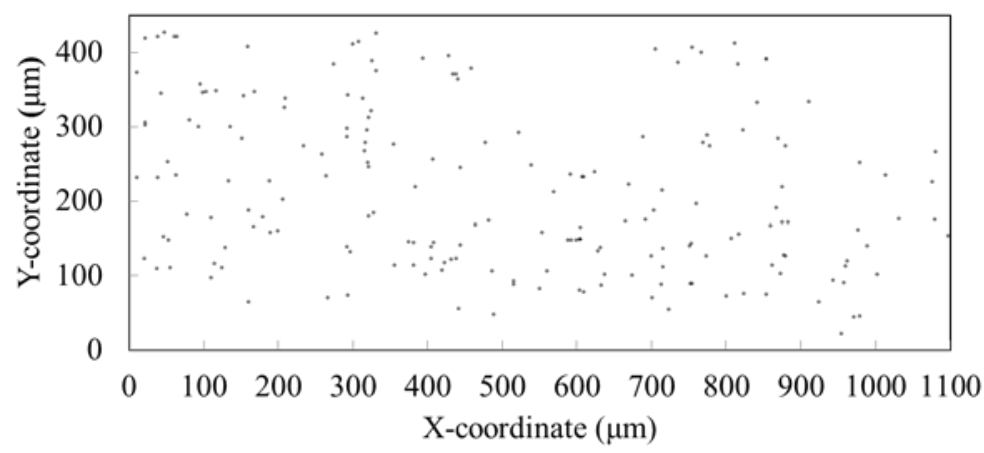

(b)

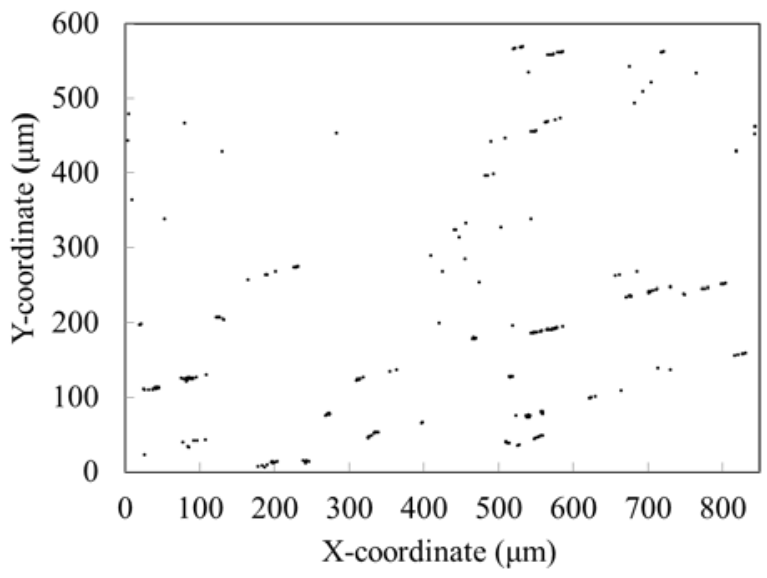

(c)

Fig. B9. Sample aged at $1500{ }^{\circ} \mathrm{C}$ for $500 \mathrm{~h}$ - digitized precipitate locations corresponding to the (a) longitudinal section, (b) transverse section, and (c) the rolling surface. The horizontal is approximately along the rolling direction in (a) and (c) and the long transverse direction in (b). The center of each dot represents the location of a single precipitate. 


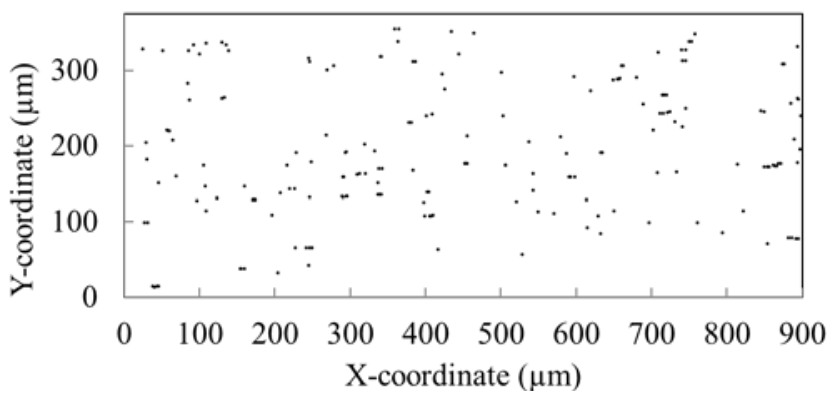

(a)

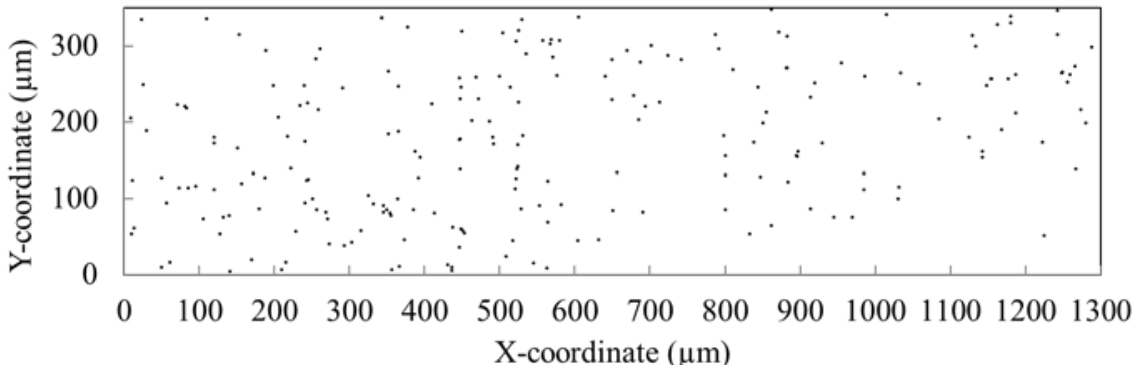

(b)

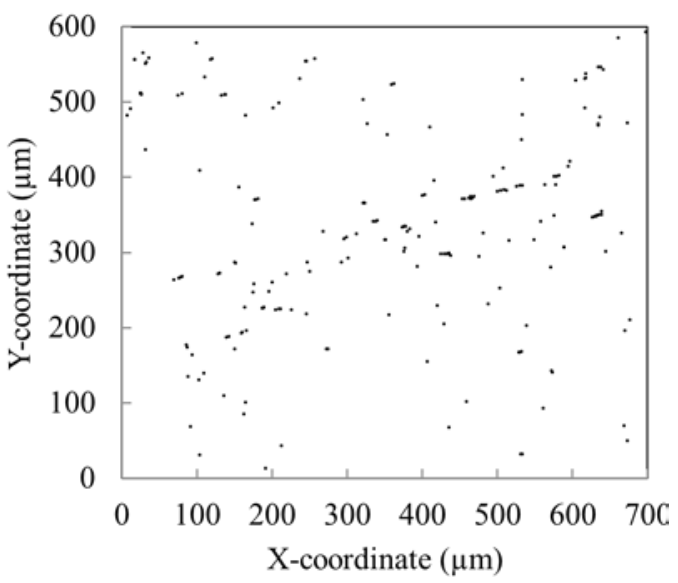

(c)

Fig. B10. Samples aged at $1500{ }^{\circ} \mathrm{C}$ for $1000 \mathrm{~h}$ - digitized precipitate locations corresponding to the (a) longitudinal section, (b) transverse section, and (c) the rolling surface. The horizontal is approximately along the rolling direction in (a) and (c) and the long transverse direction in (b). The center of each dot represents the location of a single precipitate. 
APPENDIX C. FREQUENCY DISTRIBUTION HISTOGRAMS OF THE PRECIPITATE SPACING 



\section{FREQUENCY DISTRIBUTION HISTOGRAMS OF PRECIPITATE SPACING}
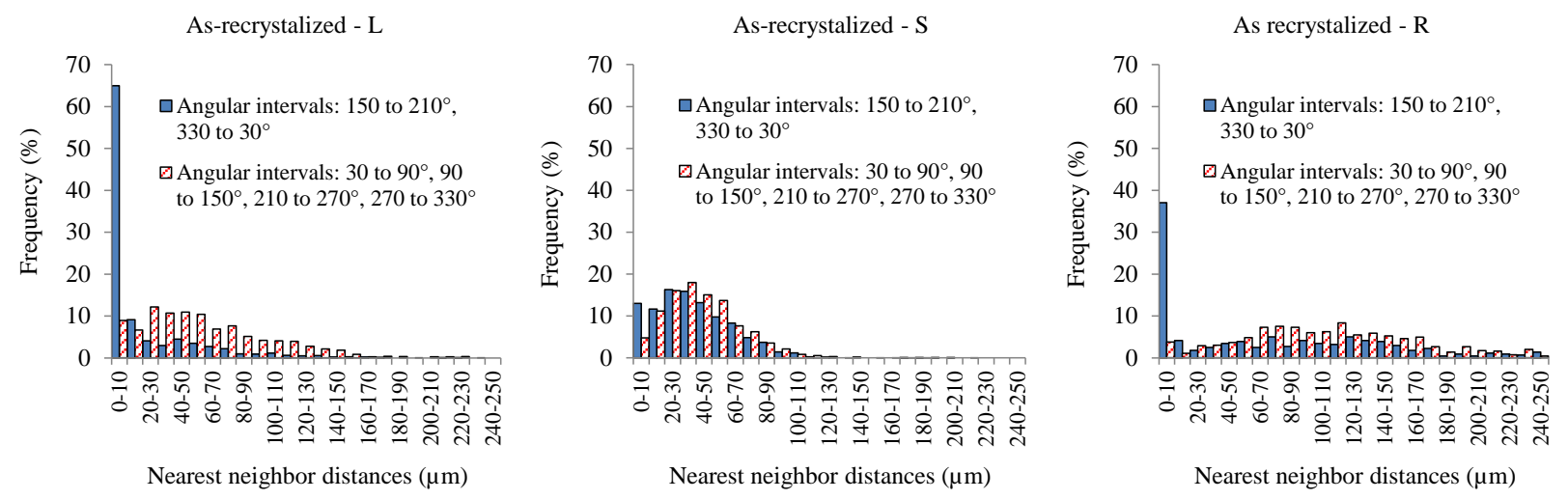

Fig. C1. As-recrystallized sample. Frequency distribution histograms of the near neighbor precipitate distances for specific angular intervals for the $L, S$, and $R$ surfaces (left to right). 

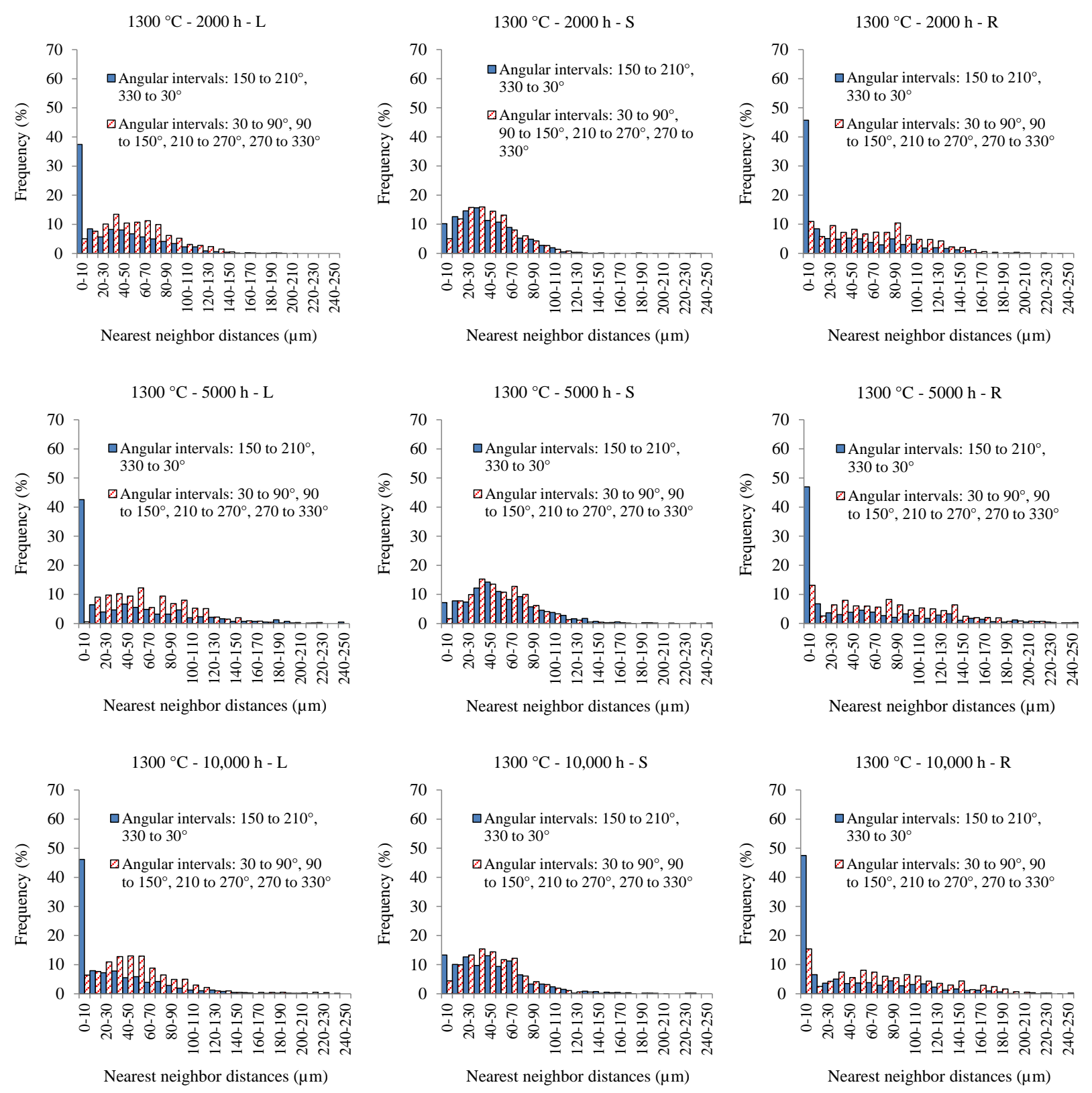

Fig. C2. Samples aged at $1300^{\circ} \mathrm{C}$. Frequency distribution histograms of the near neighbor precipitate distances at specific angular intervals for the $\mathrm{L}, \mathrm{S}$, and $\mathrm{R}$ surfaces (left to right) after aging times of 2000 (top), 5000 (middle), and 10,000 h (bottom). 


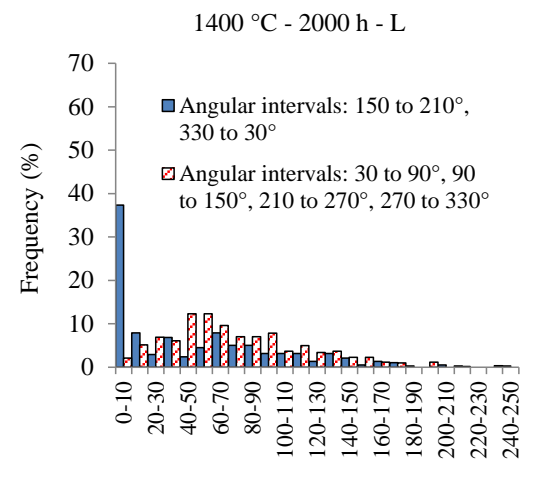

Nearest neighbor distances $(\mu \mathrm{m})$

$1400{ }^{\circ} \mathrm{C}-5000 \mathrm{~h}-\mathrm{L}$

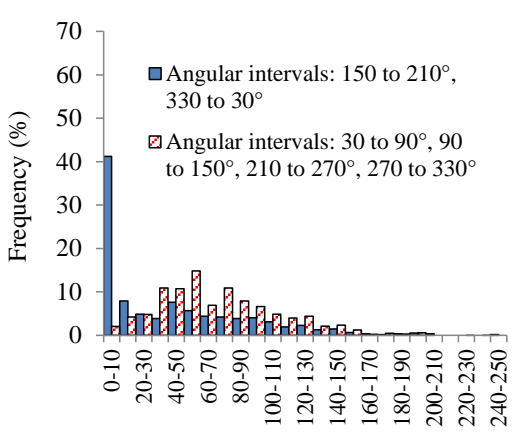

Nearest neighbor distances $(\mu \mathrm{m})$

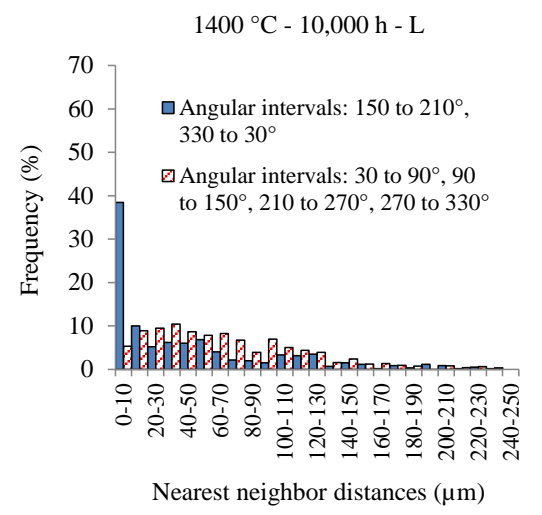

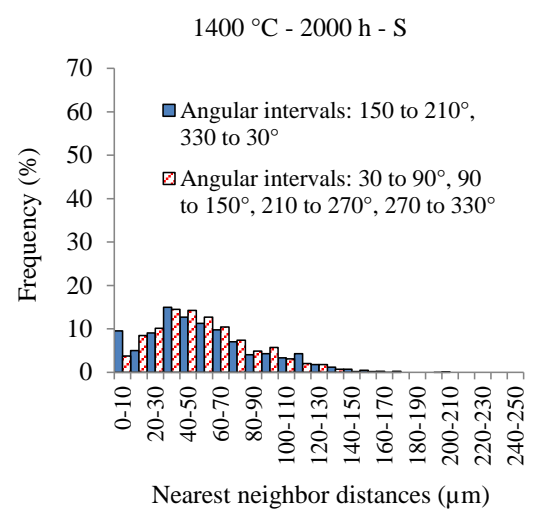

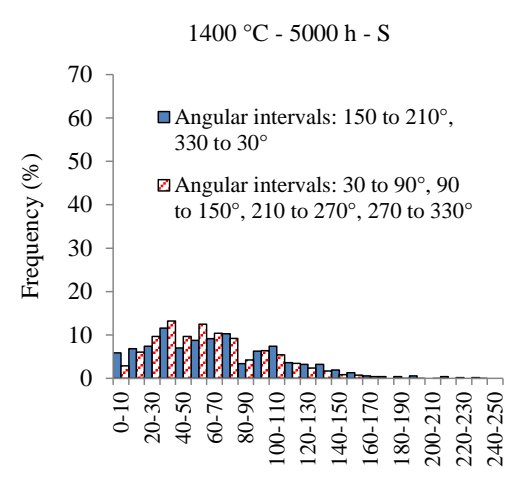

Nearest neighbor distances $(\mu \mathrm{m})$

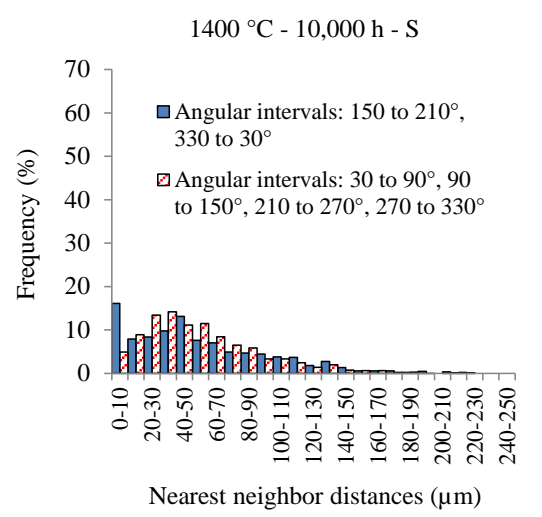

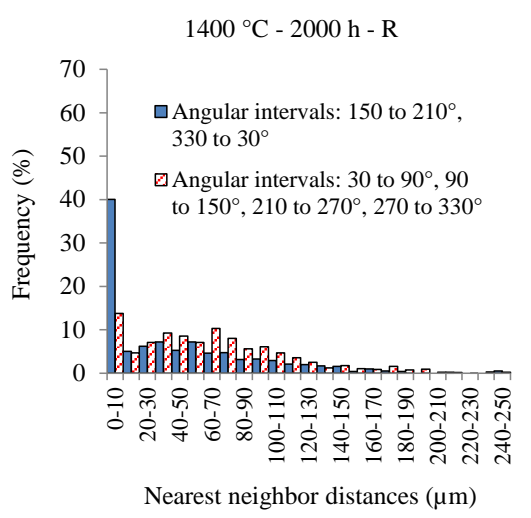

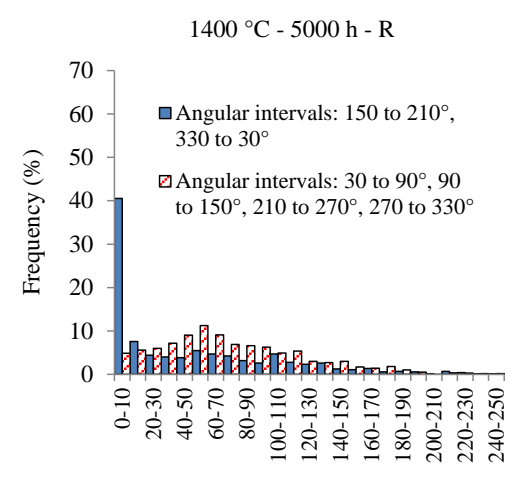

Nearest neighbor distances $(\mu \mathrm{m})$

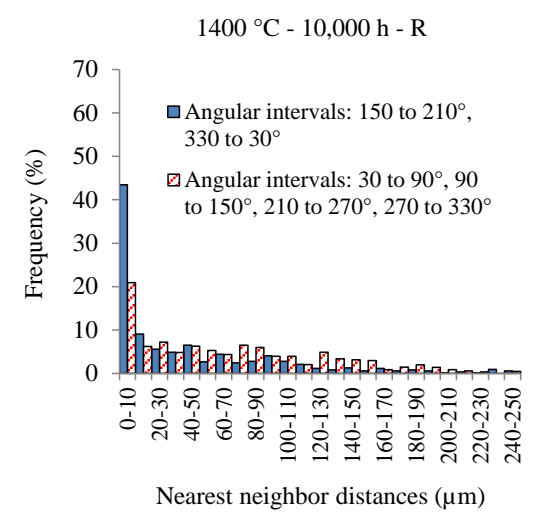

Fig. C3. Samples aged at $1400{ }^{\circ} \mathrm{C}$. Frequency distribution histograms of the near neighbor precipitate distances at specific angular intervals for the $L, S$, and $R$ surfaces (left to right) after aging times of 2000 (top), 5000 (middle), and 10,000 h (bottom). 


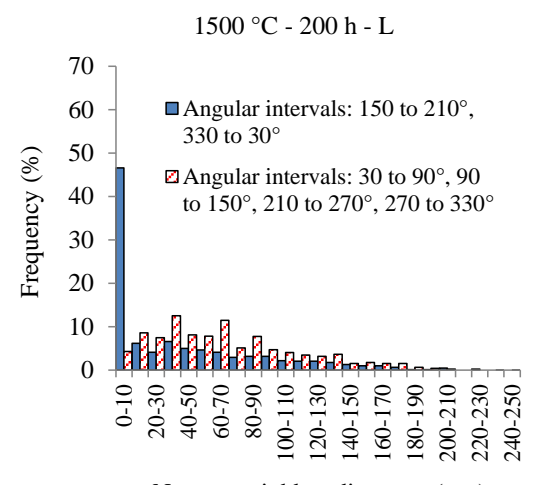

Nearest neighbor distances $(\mu \mathrm{m})$

$1500{ }^{\circ} \mathrm{C}-500 \mathrm{~h}-\mathrm{L}$

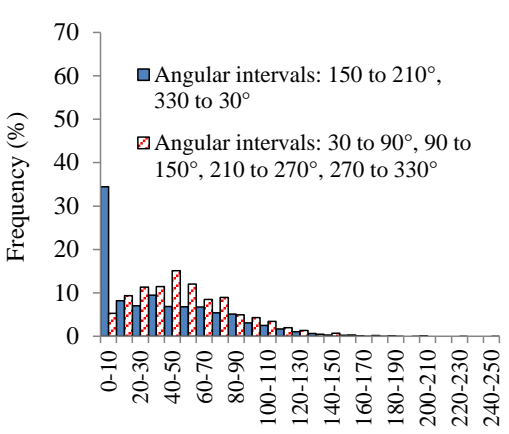

Nearest neighbor distances $(\mu \mathrm{m})$

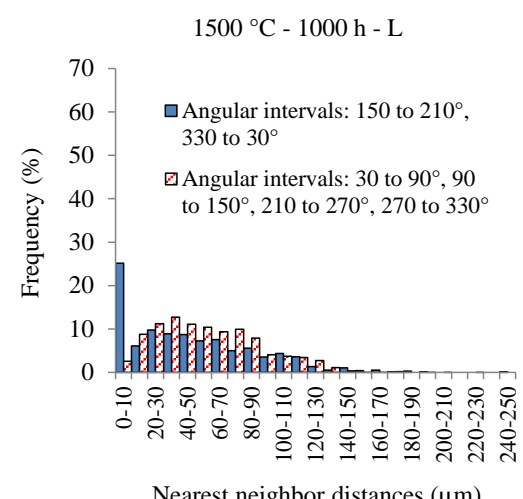

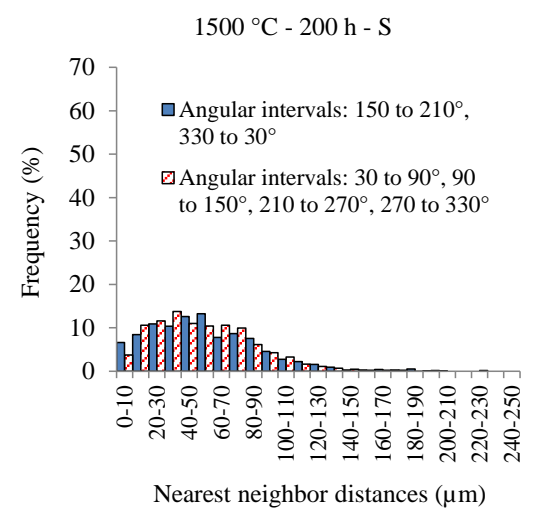
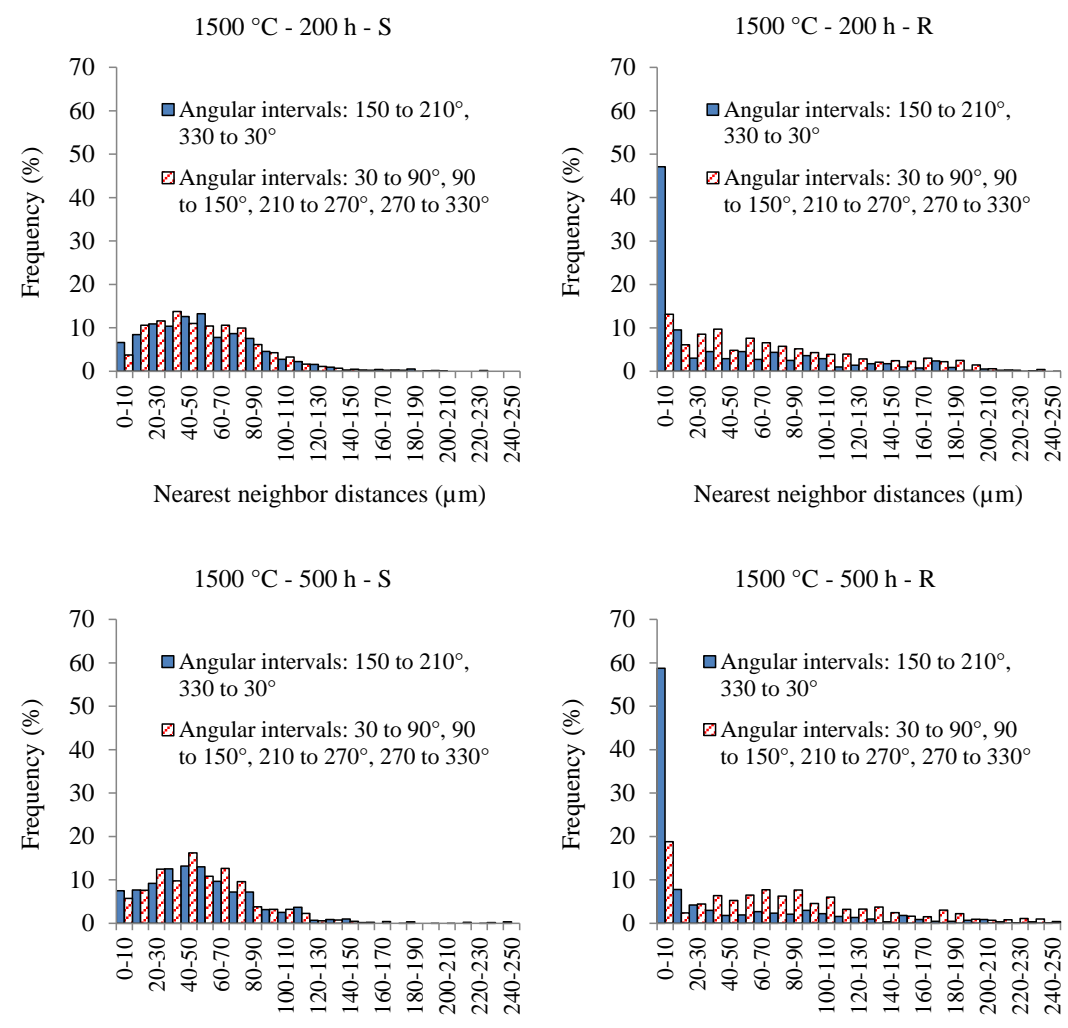

Nearest neighbor distances $(\mu \mathrm{m})$

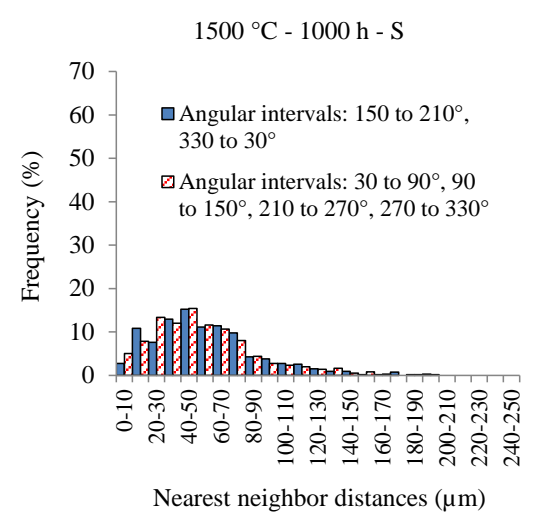

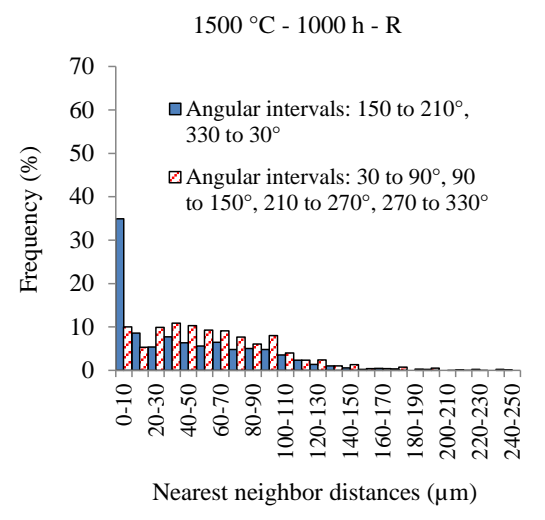

Fig. C4. Samples aged at $1500{ }^{\circ} \mathrm{C}$. Frequency distribution histograms of the near neighbor precipitate distances at specific angular intervals for the $\mathrm{L}, \mathrm{S}$, and $\mathrm{R}$ surfaces (left to right) after aging times of 200 (top), 500 (middle), and $1000 \mathrm{~h}$ (bottom). 